\title{
A mapping of labor mobility costs in the developing world ${ }^{i s}$
}

\author{
Erhan Artuc ${ }^{\text {a,* }}$, Daniel Lederman ${ }^{\mathrm{b}}$, Guido Porto ${ }^{\mathrm{c}}$ \\ a Development Research Group, The World Bank, 1818 H St. NW, Washington, DC 20433, United States \\ b Latin America and the Caribbean, The World Bank, 1818 H St. NW, Washington, DC 20433, United States \\ c Universidad Nacional de La Plata, Departamento de Economia, Calle 6 e/47 y 48, 1900 La Plata, Argentina
}

\section{A R T I C L E I N F O}

\section{Article history:}

Received 23 July 2013

Received in revised form 24 October 2014

Accepted 24 October 2014

Available online 6 November 2014

\section{JEL classification:}

F16

D58

$\mathrm{J} 2$

J6

Keywords:

World labor mobility costs

Wage dynamics

Employment dynamics

\begin{abstract}
A B S T R A C T
Estimates of labor mobility costs are needed to assess the responses of employment and wages to trade shocks when factor adjustment is costly. Available methods to estimate those costs rely on panel data, which are seldom available in developing countries. We propose a method to estimate mobility costs using readily obtainable data worldwide. Our estimator matches the changes in observed sectoral employment allocations with the predicted allocations from a model of costly labor adjustment. We estimate a world map of labor mobility costs and we use those estimates to explore the response of labor markets to trade policy.
\end{abstract}

C 2014 Published by Elsevier B.V.

\section{Introduction}

Labor market frictions, such as moving costs, firing-hiring costs, or sector-specific skills, make labor adjustment typically costly. ${ }^{1}$ In this setting, a trade shock will only induce a gradual response of wages and employment and this pattern of sluggish labor adjustment has

\footnotetext{
is We want to thank Irene Brambilla for the discussion. The detailed comments of two anonymous referees and the Editor greatly improved our paper. David Jaume provided a very valuable research assistance. The comments from the seminar participants at the Universidad de La Plata, Universidad de San Andres and the World Bank are greatly appreciated. We are also grateful to M. Haddad, B. Hoekman, and A. Mattoo for the support with the project. This paper is part of the Trade and Labor Adjustment Costs program led by the International Trade Department of the World Bank (PRMTR). The authors also gratefully acknowledge the funding from the Multi-Donor Trust Fund for Trade of the World Bank. Guido Porto acknowledges the support from the R4D on Employment funded by the Swiss National Science Foundation and the Swiss Development Cooperation.

* Corresponding author.

E-mail address: guido.porto@depeco.econo.unlp.edu.ar (G. Porto).

1 Labor immobility is documented in Wacziarg and Wallack (2004), who show little inter-industry flows after liberalization across countries, and Muendler (2010) and Menezes-Filho and Muendler (2011), who show that the absorption of displaced workers from de-protected industries in Brazil was very slow. Labor immobility is also indirectly suggested by the presence of wage differentials, created in part by tariff protection (Attanasio et al., 2004; Goldberg and Pavcnik, 2005; Galiani and Porto, 2010).
}

important welfare implications. ${ }^{2}$ The assessment of these labor market responses requires estimates of the costs of labor mobility, but these estimates are seldom available in developing countries. In this paper, our aim is to create a map of estimates of labor mobility costs across the developing world and to use these estimates to explore labor market responses to trade shocks.

We set up a dynamic model of sectoral employment choices and we estimate it for a large sample of developing countries. We adopt the labor adjustment analytical framework of Artuc et al. (2010), where workers can move across sectors (e.g., in response to wage differences) at a cost. This cost has a common and an idiosyncratic component. The common component captures the average mobility cost of a labor market friction, while the idiosyncratic cost captures worker-specific costs. The parameters governing these costs can only be estimated with panel data, which are hard to find in developing countries. ${ }^{3}$ To

\footnotetext{
2 The estimation of the impacts of trade liberalization in the presence of imperfect labor mobility is a major ongoing theme in the recent trade literature. Structural models of the dynamics of costly labor adjustment following trade policy and trade shocks include Artuc et al. (2008, 2010), Coşar (2013), Coşar et al. (2013), Davidson and Matusz (2000, 2004a 2004b, 2006a, 2006b, 2010), Dix-Carneiro (2014), and Kambourov (2009).

${ }^{3}$ Panel data provide information on the level of the gross employment flows (which identify the average mobility cost) and on the responsiveness of those flows to the observed wage differentials (which identifies the idiosyncratic component).
} 
overcome this limitation, we adapt the model and propose a novel estimation strategy (a minimum distance estimator) that requires only a time series of cross-sections of sectoral employment and wages-more easily obtainable data. Without the gross flows from the panels, we use net flows to identify the common mobility cost by matching the response of those flows to observed wage differences. We also need to impose a normalization of the idiosyncratic costs. This normalization turns out to be appropriate because our model allows for utility compensating differentials across sectors and also because our estimates are robust to small departures from this normalization. In the end, we generate a robust cross-country pattern of mobility costs caused by labor market frictions. This allows us to assess the responses to trade shocks in the presence of costly labor adjustment in a wide array of countries.

We use the United Nations Industrial Development Organization (UNIDO) database, which provides information on labor allocations and wages in the manufacturing sector, to estimate a map of the labor mobility costs for 25 developed countries and 31 developing countries. We estimate large costs of labor mobility. On average, the labor mobility costs in developing countries are equivalent to 3.71 times the annual wage. In the developed countries, the mobility costs are 2.76 times the annual wage-much lower, as expected. The highest costs are estimated in Sub-Saharan Africa (4.00), Eastern Europe and Central Asia (3.95), South Asia (3.88), Middle East and North Africa (3.59), East Asia and the Pacific (3.46), and Latin America (3.23). Labor mobility costs are negatively correlated with per capita GDP and positively correlated with less-developed, low-quality labor markets. The mobility costs are also positively correlated with other frictions, distortions and constraints in the economy.

To illustrate how our estimates of labor mobility costs can be used for policy analysis, we run simulations of the labor market responses to trade liberalization. For each developing country, we separately explore the impacts of a hypothetical decrease in the prices of Food and Beverages and Textiles (due to a worldwide decline in food demand, for instance). The magnitude of the labor mobility costs matters for the responses of these economies to such a trade shock. Typically, countries only reach close to the steady state after 6 years and the higher the mobility costs are, the longer this transition takes. This imperfect adjustment is costly. We estimate measures of trade adjustment costs and these estimates vary widely across countries. On average, the costs of adjustment to a trade shock in the food sector are as high as the actual welfare impacts caused by that shock. The median cost of adjustment is roughly half the actual welfare effects.

The rest of the paper is organized as follows. Section 2 introduces the structural model of labor mobility costs and, Section 3 discusses the estimation algorithm and the identification mechanism. The mapping of the estimates of the labor mobility costs is in Section 4. Section 5 assesses the identification assumptions of our model and the potential biases created by violations of those assumptions. Section 6 presents the simulations of the impacts of trade shocks. Finally, Section 7 concludes.

\section{A model of labor mobility costs}

Our model of labor mobility costs is based on Artuc et al. (2010). There are $N$ sectors in the economy, $M$ manufacturing sectors and one non-manufacturing sector. ${ }^{4}$ Sector $i$ produces a good using labor $L^{i}$ and a specific factor (such as capital or land) with the following technology

$Q_{t}^{i}=F^{i}\left(L_{t}^{i}, s_{t}\right)$,

where $s_{t}$ captures the overall state of the economy at time $t$. The state variable summarizes the role of shocks to prices, technology, policies, and to the specific factor. For estimation purposes, because of the

\footnotetext{
${ }^{4}$ In other settings, this "residual" sector could also include unemployment or informality. See our discussion below.
}

aggregate nature of our data, we will assume that workers have perfect foresight so that they can make perfect predictions of the evolution of $s_{t}$ (see Section 3). With more detailed data, as in Artuc et al. (2010), the model can accommodate first order Markov processes for $s_{t}$. For presentational purposes, we keep a general notation in this section, and simplify the formulas for the case of perfect foresight in the estimation section. Firms are homogeneous and choose employment to maximize profits. The representative firm hires labor $L_{t}^{i}$ so as to equalize the equilibrium wage with the value of the marginal product of labor

$w_{t}^{i}=p_{t}^{i} \frac{\partial F^{i}\left(L_{t}^{i}, s_{t}\right)}{\partial L_{t}^{i}}$,

where $w_{t}^{i}$ is the wage in sector $i$ and $p_{t}^{i}$ is the price of good $i$.

At a given time period, each agent is employed in a sector and earns the sectoral market wage. At the end of each time period $t$, the agent chooses a sector of employment for the next period, $t+1$. If the utility differential is larger than the cost of moving, the workers move. This determines a new vector of equilibrium labor allocations. We can then estimate the key moving cost parameters by matching the employment predictions of the model with the employment allocations observed in the data.

A worker employed in sector $i$ at time $t$ earns the current sector specific wage $w_{t}^{i}$ and enjoys a sector specific (utility) effect denoted by $\eta^{i}$. Total instantaneous utility is thus $u_{t}^{i}=w_{t}^{i}+\eta^{i}$. These $\eta^{i}$ can be interpreted as compensating differentials across sectors. Both $w_{t}^{i}$ and $\eta^{i}$ are common to all workers in a given sector so that there is no worker heterogeneity. ${ }^{5}$ The agent observes both $w$ and $\eta$, but only $w$ is observed in the data.

At the end of each time period $t$, the agent chooses the next period sector of employment based on the expected stream of future wages (which depends on the state variable $s_{t}$ ) and on the moving costs. The cost of choosing alternative $j$ for agent $l$ who is currently in sector $i$ is $C+\varepsilon_{t}^{j, l}$. The "moving cost" has two components, a deterministic part, $C$, common to all agents, and a random part, $\varepsilon_{t}^{j, l}$, specific to agent $l$. Each worker thus faces a vector of moving $\operatorname{costs} \varepsilon_{t}^{l}$. All agents are identical except for their individual moving cost shocks $\varepsilon_{t}^{l}$ and their current sector. Hence, the state of each agent can be summarized by his/her sector $i$, the vector of shocks $\varepsilon_{t}^{l}$ and the aggregate state $s_{t}$ (which, under perfect foresight as in the estimation section, is known). We assume that $C=0$ if agents stay in their current sector. At the end of time $t$, the random component of the "moving cost," $\varepsilon_{t}^{j, l}$, is revealed.

Agents are risk neutral, have rational expectations and a common discount factor $\beta<1$. Let $U^{i}\left(s_{t}, \varepsilon_{t}^{l}\right)$ be the present discounted choice-specific utility of agent $l$ currently employed in sector $i$. The Bellman equation is

$U^{i}\left(s_{t}, \varepsilon_{t}^{l}\right)=w_{t}^{i}+\eta^{i}+\max _{j}\left\{\beta E_{t, \varepsilon} U^{j}\left(s_{t+1}, \varepsilon_{t+1}^{l}\right)-1_{i \neq j} C-\varepsilon_{t}^{j, l}\right\}$,

where $1_{i \neq j}$ is the indicator function equal to 1 if $i \neq j$, i.e. if the agent moves, and zero otherwise. Note that, in Eq. (3), the workers take expectations, $E_{t, \varepsilon}$, at time $t$ over the idiosyncratic shocks $\varepsilon_{t+1}$ as well as on the state $s_{t+1}$.

We now need to solve the model to compute the equilibrium flows of workers across sectors. This solution delivers employment allocations for all sectors $i$ and periods $t$, and we can thus recover the structural parameters by matching the employment solution of the model with the employment levels observed in the data, our task in Section 3. To find the solution, let $V^{j}\left(s_{t}\right)$ be the expected value of $U$, conditional on the vector of idiosyncratic shocks $\varepsilon_{t}^{l}$, i.e., $V^{j}\left(s_{t}\right)=E_{\varepsilon} U^{j}\left(s_{t}, \varepsilon_{t}^{l}\right)$. Take expectations of Eq. (3) with respect to agent specific shocks to get

$V^{i}\left(s_{t}\right)=w_{t}^{i}+\eta^{i}+E_{\varepsilon} \max _{j}\left\{\beta E_{t} V^{j}\left(s_{t+1}\right)-1_{i \neq j} C-\varepsilon_{t}^{j, l}\right\}$.

\footnotetext{
${ }^{5}$ As explained below, we work only with aggregate data, and therefore this is an unavoidable assumption. Dix-Carneiro (2014) introduces worker heterogeneity in a related structural model of labor mobility costs.
} 
In principle, the model can be solved for any distributional assumption for the idiosyncratic shocks $\varepsilon$. As it is standard in discrete choice model, we assume that $\varepsilon$ is distributed iid extreme value type I with location parameter $-\nu \gamma$, scale parameter $\nu$, and $\operatorname{cdf} F(\varepsilon)=$ $\exp (-\exp (-\varepsilon / \nu-\gamma))$, where $E(\varepsilon)=0, \operatorname{Var}(\varepsilon)=\pi^{2} \nu^{2} / 6$ and $\gamma$ is Euler's constant. This assumption simplifies the Bellman equation and makes it tractable (McFadden, 1973).

We can now derive the employment allocations implied by the model. Let $m_{t}^{i j}$ be the ratio of agents who switch from sector $i$ to sector $j$. This can be interpreted as gross flows from $i$ to $j$, or the probability of choosing $j$ conditional on $i$. The total number of agents moving from $i$ to $j$ is equal to $y_{t}^{i j}=L_{t}^{i} m_{t}^{i j}$, where $L_{t}^{i}$ is the number of agents who are in $i$ at time $t$. Under the extreme value distributional assumption, the gross flow $m_{t}^{i j}$ can be written as

$$
m^{i j}\left(s_{t}\right)=\frac{\exp \left(\left(E_{t} V^{j}\left(s_{t+1}\right)-1_{i \neq j} C\right) \frac{1}{v}\right)}{\sum_{k=1}^{N} \exp \left(\left(E_{t} V^{k}\left(s_{t+1}\right)-1_{i \neq k} C\right)\left(\frac{1}{v}\right)\right)}
$$

for $i \neq j$. For workers that stay, $1_{i \neq j} C=0$ so that $m_{t}^{i i}=\exp \left(\left(E_{t} V_{t+1}^{j}\right) / \nu\right) /$ $\sum_{k=1}^{K} \exp \left(\left(E_{t} V_{t+1}^{k}\right) / \nu\right)$.

We can also write the ex-ante value function as

$V^{i}\left(s_{t}\right)=w_{t}^{i}+\eta^{i}+\beta E_{t} V^{i}\left(s_{t+1}\right)+\Omega^{i}\left(s_{t}\right)$,

where $\Omega\left(s_{t}\right)^{i}$ is the option value for workers in sector $i$ (the ex-ante value of switching sectors). With perfect foresight, this simplifies to $V^{i}\left(s_{t}\right)=w_{t}^{i}+\eta^{i}+\beta V^{i}\left(s_{t+1}\right)+\Omega^{i}\left(s_{t}\right)$.

Finally, the allocation of labor between sectors is given by:

$L_{t+1}^{j}=\sum_{k \neq j} m^{k j}\left(s_{t}\right) L_{t}^{k}+m^{j j}\left(s_{t}\right) L_{t}^{j}$

There are four key pieces in the model: the common mobility costs, $C$, the variance of the idiosyncratic mobility $\operatorname{costs}, \nu$, the compensating differentials, $\eta^{i}$, and the wage differentials. At each time period, workers compare the costs and benefits of changing employment sector. The benefits are given by the utility differentials, that is the wage differentials net of the compensating differentials. The workers move when the utility differentials are larger than the mobility costs, inclusive of the idiosyncratic benefits. In the end, given the utility differentials, the flow of workers across sectors depends on $C$ and $\nu$, which are the parameters that we want to estimate.

\section{Estimation}

Our goal in this paper is to create the most comprehensive map of estimates of labor mobility costs possible. Artuc et al. (2010) derive the estimators of these mobility costs based on panel data. The panels are used to build measures of gross employment flows across sectors that, together with utility compensating differentials, identify $C, \nu$, and $\eta^{i}$. In many countries, where the needed panel data is not available, this approach cannot be implemented. For many of these countries, there is availability of time series of sector-level employment and wages, for example in the UNIDO database. In this section, we derive the estimators of the mobility costs based on this readily available data.

\subsection{The UNIDO data}

It is convenient to begin with a description of the data, because the available data imposes some restrictions on the estimation algorithm. In the analysis, we use INDSTAT4, the UNIDO Industrial Statistics Database for the period 1986-2007. The dataset provides information on the number of establishments, number of employees, wages, output, value added, and gross fixed capital formation. For our purposes, we need information on employment and wages for the estimation and also on value added for the simulations (see Section 6 below). From these data, we build series for the wage streams $w_{t}^{i}$ and for the labor allocations $L_{t}^{i}$, for sector $i$ at time $t$. For the estimation, we aggregate the data into eight major sectors, namely Metals \& Minerals, Chemicals \& Petroleum Products, Machinery, Food \& Beverages, Wood Products, Textiles \& Clothing, Miscellaneous Equipments, and Motor Vehicles. The UNIDO data has a good coverage of the manufacturing sector but does not cover the non-manufacturing sector. To overcome this limitation, we use national account data to construct measures of labor allocations in the non-manufacturing sector, which we label as sector 1 . Note that we do not observe wages for the non-manufacturing sector. In the end, our data comprises time series of employment allocations for both non-manufacturers and manufacturers, $L_{t}^{1}$ and $L_{t}^{i}$, and wages for manufacturers, $w_{t}^{i}$. Wages (utilities) in the nonmanufacturing sector, $u_{t}^{1}$, will be calibrated from the data.

\subsection{The estimator}

We propose a simulation estimator where we compare the labor allocations simulated with our structural model with the labor allocations observed in the data. Concretely, we define a minimum distance estimator that matches changes in employment allocations for all the manufacturing sectors across time:

$$
\hat{C}=\underset{C ; \eta, \mathbf{u}^{1}}{\operatorname{argmin}} \sum_{t=1}^{T-1} \sum_{i=1}^{N} \omega_{t}^{i}\left(\left(\widetilde{L}_{t+1}^{i}\left(C ; \eta, \mathbf{u}^{1}\right)-\widetilde{L}_{t}^{i}\left(C ; \eta, \mathbf{u}^{1}\right)\right)-\left(L_{t+1}^{i}-L_{t}^{i}\right)\right)^{2},
$$

where $\widetilde{L}_{t}^{j}$ are the employment prediction of the model and $\omega_{t}^{i}$ are weights used for efficiency. The minimization search is done over $C$, the vector of $\eta$ for the manufacturing sectors, and the time vector of utilities for the non-manufacturing sector $\mathbf{u}^{1}=\left[u_{1}^{1}, \ldots, u_{T}^{1}\right]$. Identification depends on the response of employment allocations to wage differences in the data. Before discussing identification issues in detail below, we need to talk about the implementation of the estimator.

Note first that the nature of our cross-section data imposes some restrictions on the parameters we can estimate. In particular, given the data on employment allocation, and thus the lack of data on gross flows, we can only identify $C / \nu$, the ratio of the common mobility cost $C$ and the variance of the utility shocks $\nu$, but we cannot separately identify these parameters. To pin down $C$, we plug in the best possible estimate of $\nu$. To obtain it, we work with the CPS micro-data with detailed wage information as well as gross labor flows and employ the method used in Artuc and McLaren (2014) and Artuc, Bet, Brambilla, and Porto (2014). This paper adds sectoral utility fixed effects and utilize maximum likelihood methods applied to conditional choice probability models. If we use these MLE methods with the U.S. CPS data, the estimate for the baseline is $\nu=0.60 .^{6}$

Second, we need an assumption about the formation of workers' expectations regarding the state of the economy $s_{t}$. The state $s$ captures various aggregate shocks in the economy, including technology shocks, policies, and price shocks. Again, given the limitations of our data, we impose a perfect foresight assumption, namely $E_{t} s_{\tau}=s_{\tau}$ for any $\tau \geq t$, so that there is no aggregate uncertainty. We also assume that the state of the economy remains constant after $T$, the last year in the UNIDO data, so that $s_{T+x}=s_{T}$, for $x>0$ and the optimization problem ends at $T$. These assumptions, which imply that workers make perfect predictions about the wage stream, are useful because they save us from solving the expectations numerically in the Bellman equations embedded in the minimization algorithm. More concretely, we have that $E_{t} V^{i}\left(s_{t+1}\right)=V^{i}\left(s_{t+1}\right)$, so that we can solve the system of values $V_{t}^{i}$

\footnotetext{
${ }^{6}$ These methods also estimate $C=1.762$, and we exploit this below to further assess our estimator (in Section 5). We also show in Section 5 and in the Online Appendix to the paper that this normalization of $\nu$ turns out to be appropriate for our purposes. The Online Appendix can be found at www.https://sites.google.com/site/guidoportounlp/.
} 
for $t=1, \ldots, T$ from Eq. (6). It is important to note that the predictions of the model can depart from the data even with perfect foresight because of the randomness of the idiosyncratic utility shocks. In fact, if the manufacturing sector is small, as it often is in our target countries, then $\varepsilon$ can account for significant deviations of the model. If we instead wanted to accommodate aggregate shocks to $s_{t}$, such as iid or first order Markov shocks, we run into two problems. We do not have sufficient information in the data to specify the nature of these shocks (i.e., the variance or the transition probabilities). More importantly, even under arbitrary assumptions about the aggregate shocks, the computational burden would make our estimation unfeasible. ${ }^{7}$ In addition, with perfect foresight, there is no need to specify functional forms for the production functions. The wages observed in the data are equilibrium wages (so that the wage is equal to the marginal product of labor for given production functions). The stream of wages thus convey all the information about the economy that the workers need, together with the expected idiosyncratic shocks, to make the best moving decision for different $C{ }^{8}$ We carefully assess the implications of these assumptions with Monte Carlo simulations and with micro-data analysis in Section 5.

Finally, in order to simplify the numerical search given the large number of parameters and the limited data, we find the utility differentials $\left\{u_{t}^{1}\right\}$ and the compensating differentials $\eta^{i}$ that simultaneously solve the following system of equations:

$\widetilde{L}_{t}^{1}\left(\mathbf{u}^{1}, \eta ; C / \nu\right)=L_{t}^{1}$

for all $t$, and, for each sector $i$,

$\frac{1}{T} \sum_{t} \widetilde{L}_{t}^{i}\left(\mathbf{u}^{1}, \eta ; C / \nu\right)=\frac{1}{T} \sum_{t} L_{t}^{i}$

where $T$ is the number of time periods in the data. This is a calibration procedure where we match $\left\{u_{t}^{1}\right\}$ and $\eta$ such that the predictions of the model match both the whole time series of non-manufacturing sector labor allocations and the average employment for each sector $i$. The vectors $\mathbf{u}^{1}$ and $\eta$ are re-calibrated in each step of the minimization search. In this step of the procedure, our estimator has a flavor similar to the estimator in Goolsbee and Petrin (2004) in the sense that they match micro-data to recover the parameters and aggregate moments to recover the fixed-effects. The key difference is that Goolsbee and Petrin have much more detailed disaggregated data and thus can estimate rather than calibrate the fixed-effects, as we do here.

To implement the estimator, we start with guesses for the mobility costs, $C$, the compensating differentials for the manufacturing sectors, $\eta^{i}$, and the utility differentials for the non-manufacturing sector, $\left\{u_{t}^{1}\right\}$. Given these guesses, we solve the model. We calculate the values $V_{t}^{i}, V_{t}^{1}$ using Eq. (6) and the gross flows, $m_{t}^{i j}$ and, with them, we predict the next period labor allocation in sector $j, \widetilde{L}_{t+1}^{j}$,

$\widetilde{L}_{t+1}^{j}=\sum_{i=1}^{K} \widetilde{L}_{t}^{i} m_{t}^{i j}$

where $\widetilde{L}_{1}^{i}=L_{1}^{i}$ for $t=1$. These predictions are then compared with the data and the guesses are updated until convergence. The guesses for $\eta^{i}$

\footnotetext{
${ }^{7}$ For the estimation and simulation of the model, we use streamlined Fortran algorithms to increase the speed of computations. In some experiments we run with arbitrary aggregate shocks, it can take weeks of computing time to find the $C$ that minimizes Eq. (8).

8 Note that the structure of the economy could be different (production functions could be CES instead of Cobb-Douglas), but we would estimate the same Cs we are reporting. With alternative assumptions about expectations or shocks, such as iid shocks or AR(1) shocks, this separation between estimation and simulation may not be achieved. If so, then the estimation would require simulation, which in turn would require some knowledge about the nature of the aggregate shocks and would also require us to fully specify the structure of the economy. For the simulation of section 6 , however, it will be necessary to specify the functional form of the production and demand functions. See also Artuc et al. (2010) for a thorough discussion.
}

and $\left\{u_{t}^{1}\right\}$ are updated with the calibration step. The guess for $C$ is updated with the numerical minimization of Eq. (8), conditional on the updated $\eta^{i}$ and $\left\{u_{t}^{1}\right\} .{ }^{9}$ To achieve efficiency, the model is estimated in two steps. We first use the identity matrix as the weighting matrix and we then plug in the residuals from this step in $\omega_{t}^{i}$.

The variance of $C$ can be derived following straightforward asymptotic theory for extremum estimators as follows. Given the solution $\hat{C}$, let $\hat{\Lambda}_{t+1}^{i}=\hat{L}_{t+1}^{i}\left(\hat{C} ; \eta, \mathbf{u}^{1}\right)-\hat{L}_{t}^{i}\left(\hat{C} ; \eta, \mathbf{u}^{1}\right)$ be the predicted employment changes and let $\Lambda_{t+1}^{i}=L_{t+1}^{i}-L_{t}^{i}$ be the observed employment changes. Define

$\hat{h}_{t+1}^{i}=\frac{\partial \hat{\Lambda}_{t+1}^{i}}{\partial C} e_{t+1}^{i}$,

where $e_{t+1}^{i}=\Lambda_{t+1}^{i}-\hat{\Lambda}_{t+1}^{i}(C)$ is the residual. In the Online Appendix, we show that the estimate of the variance of $\hat{C}$ is:

$\hat{V}(\hat{C})=\frac{1}{n}\left[\frac{1}{n} \sum_{i, t} \frac{\partial \hat{h}_{t+1}^{i}}{\partial C}\right]^{-1}\left(\frac{1}{n} \sum_{i, t}\left(\hat{h}_{t+1}^{i}\right)^{2}\right)\left[\frac{1}{n} \sum_{i, t} \frac{\partial \hat{h}_{t+1}^{i}}{\partial C}\right]^{-1}$,

where $n$ is the total number of observations, summing across sectors $i$ and time $t$. This variance has to be calculated numerically, because we need numerical estimates of the first and second derivatives of $\hat{\Lambda}$.

\subsection{Identification}

The intuition underneath our estimator is simple. The structure of our model dictates how agents make moving decisions based on current employment allocations, on expectations about idiosyncratic shocks, and on other parameters such as production functions (which determine wage responses), price index weights, and technology (also assuming perfect foresight of aggregate shocks). These decisions depend on $C$. Given all the parameters of the economy, including the calibrated $\eta$ 's and $\mathbf{u}^{1}$, our procedure chooses $C$ in order to match the observed changes in sectoral employment with the predicted changes in sectoral employment. We can illustrate how well the model works by plotting these matches for one country. We do this for Colombia, which, as we show in Section 4 below, has $\hat{C}=3.96$ (a relatively high $C$ ). In the top panel of Fig. 1, we show that the model fits quite well for Colombia (as it does for all other countries in our sample).

We can further explore the mechanics of our model in the data. Given the parameters of the model, and given $C$, the workers compute the value of being employed in each sector $i$. They move if the benefits from moving (the differences in values) dominate the costs of moving (the $C$ plus any idiosyncratic cost). The model thus implies, given $C$, a positive correlation between changes in employment and worker's value differences. ${ }^{10}$ To show this in the Colombian case, we run a regression of the observed differences in employment changes in the data and the differences in workers' values predicted by our model (given the estimated $C$ ). We plot the OLS slope in the bottom panel of Fig. 1. Under the estimated $C$ for Colombia, the OLS slope is 0.0006 , with a $t$-statistic of 6.89; this is the solid line in the Figure. This illustrates the mechanics of our model.

We can also inspect what this correlation looks like under alternative mobility costs. The model can create a spuriously large correlation between employment changes and value differences if $C$ is lower than the estimated $C$ (because workers will reallocate more, ceteris paribus, when the true value of $C$ is low). Conversely, the model can produce a

\footnotetext{
${ }^{9}$ Note that this means that the calibration is done in each step of the minimization search.

${ }^{10}$ It is important to note that the model compares differences in sector's values rather than simple wage differences, because workers internalize wage dynamics as well as the option value of moving. In fact, the correlation between wage differences alone and labor reallocation may not be present at all in the data.
} 


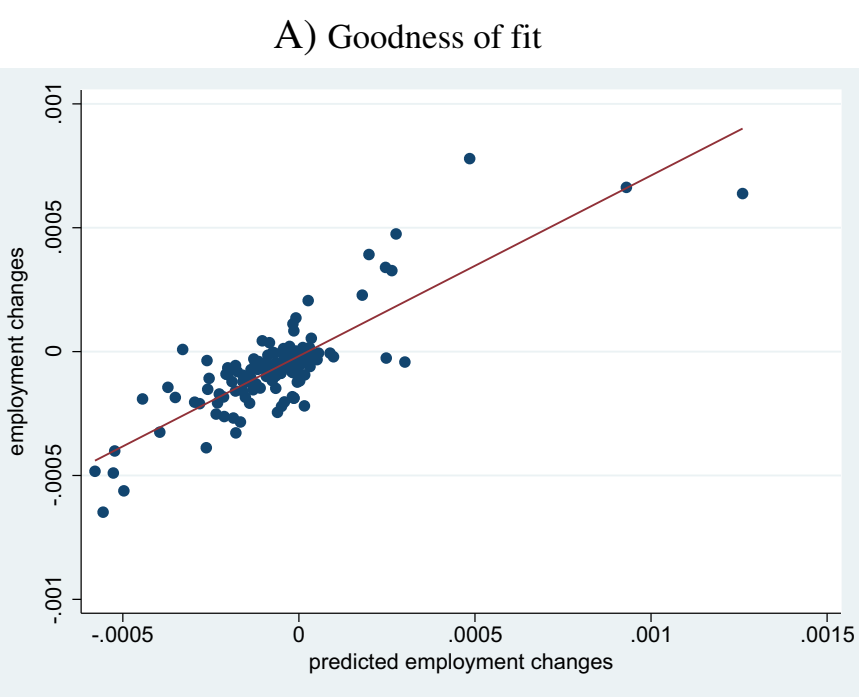

B) Model Mechanisms

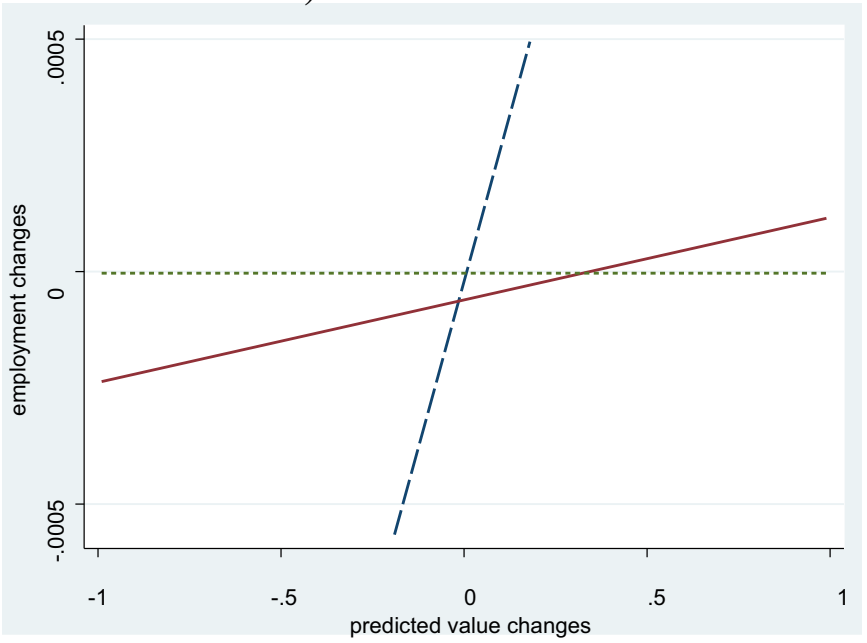

Fig. 1. Model identification. Notes. The top panel (Panel A) shows the goodness of fit of the model. The plots reveal a high correlation between employment changes and predicted employment changes (by the model). The bottom panel (Panel B) shows the model's mechanism. The graph displays the OLS slope of a regression of employment changes and predicted value changes for different $C$ s. Estimated $C=3.96$, solid line; Low- $C=$ 0.5 , long-dashed line; High- $C=20$, short-dashed line.

low correlation if $C$ is artificially high (because workers will reallocate less, ceteris paribus, when the true $C$ is high). To show this, we simulate predictions of the model for Colombia under the limiting cases of almost costless labor mobility $(C=0.5)$ and almost prohibitively costly labor mobility $(C=20)$. With almost costless mobility, a given difference in value creates excessive labor mobility. The OLS slope is 0.003 with a $t$-statistic of 6.69-the long-dashed steepest line at the bottom, panel $\mathrm{B}$, in Fig. 1. In addition, the correlation between workers' value differences and labor reallocation disappears entirely when $C$ is prohibitively high. The OLS slope is $-3.39 e-06$, and the $t$-statistic of -0.26 -the short-dashed, almost horizontal line in Fig. 1. Clearly, in both cases, the model mismatches the employment changes of the data. ${ }^{11}$

\section{A mapping of world mobility costs}

Table 1 shows the estimates of the labor mobility costs for 56 countries around the world and Fig. 2 shows the map of labor mobility costs. Table 2 reports averages for different groups of countries. For all the

\footnotetext{
11 Moreover, we can show that the objective function is minimized when $C=3.96$ (see Online Appendix).
}

Table 1

Labor mobility costs.

\begin{tabular}{|c|c|c|c|c|c|}
\hline \multirow[t]{2}{*}{ Country } & $\begin{array}{l}\text { Mobility } \\
\text { costs }\end{array}$ & $\begin{array}{l}\text { Standard } \\
\text { error }\end{array}$ & \multirow[t]{2}{*}{ Country } & $\begin{array}{l}\text { Mobility } \\
\text { costs }\end{array}$ & $\begin{array}{l}\text { Standard } \\
\text { error }\end{array}$ \\
\hline & \multicolumn{2}{|l|}{ C } & & \multicolumn{2}{|l|}{ C } \\
\hline Jordan & 5.07 & 0.97 & Iran & 3.24 & 0.22 \\
\hline Philippines & 5.06 & 0.64 & Bolivia & 3.2 & 0.34 \\
\hline Bangladesh & 4.89 & 0.14 & Hungary & 3.16 & 0.77 \\
\hline Mauritania & 4.79 & 0.26 & Romania & 3 & 0.47 \\
\hline Bulgaria & 4.67 & 2.3 & Sweden & 3 & 0.56 \\
\hline Ukraine & 4.62 & 0.3 & Italy & 2.95 & 0.67 \\
\hline Latvia & 4.58 & 0.29 & Syrian Arab Republic & 2.94 & 0.2 \\
\hline Ethiopia & 4.52 & 0.05 & El Salvador & 2.93 & 0.3 \\
\hline Azerbaijan & 4.47 & 0.78 & Czech Republic & 2.92 & 0.75 \\
\hline Cameroon & 4.2 & 0.01 & Kazakhstan & 2.88 & 0.3 \\
\hline Georgia & 4.02 & 0.69 & India & 2.87 & 0.17 \\
\hline Lithuania & 4 & 0.44 & Mongolia & 2.82 & 0.05 \\
\hline Colombia & 3.96 & 0.42 & Belgium & 2.81 & 0.41 \\
\hline Costa Rica & 3.83 & 0.37 & Slovenia & 2.76 & 2.01 \\
\hline Senegal & 3.83 & 0.02 & China & 2.75 & 0.35 \\
\hline Australia & 3.77 & 0.16 & Trinidad and Tobago & 2.74 & 0.57 \\
\hline Korea & 3.77 & 0.99 & South Africa & 2.68 & 0.37 \\
\hline United Kingdom & 3.72 & 0.37 & Poland & 2.66 & 0.33 \\
\hline Malta & 3.61 & 0.34 & Singapore & 2.57 & 1.99 \\
\hline Ecuador & 3.59 & 0.25 & Norway & 2.52 & 0.3 \\
\hline France & 3.59 & 0.19 & United States & 2.21 & 0.53 \\
\hline Spain & 3.54 & 0.41 & Argentina & 2.13 & 0.12 \\
\hline Chile & 3.47 & 0.78 & Ireland & 2.02 & 1.09 \\
\hline Indonesia & 3.46 & 0.33 & Austria & 1.9 & 0.29 \\
\hline Egypt & 3.4 & 0.5 & Netherlands & 1.82 & 1.49 \\
\hline Oman & 3.29 & 0.13 & Germany & 1.7 & 0.76 \\
\hline Russia & 3.28 & 0.17 & Finland & 1.43 & 0.35 \\
\hline Denmark & 3.25 & 0.44 & Estonia & 1.29 & 0.26 \\
\hline
\end{tabular}

Notes: Estimates of labor mobility costs $C$ using UNIDO data.

countries in the world, the average $C$ is 3.29 . This means that, when moving across sectors, the workers face a common utility cost that is equivalent to 3.29 times the annual average wage in the economy. In general, developing countries show higher Cs than developed countries. On average, the mobility cost is 2.76 for developed countries and 3.71 for developing countries. The lowest estimated costs are in Estonia, Finland, and Germany; the highest costs are in Jordan, Philippines, Bangladesh, and Mauritania. Fig. 3 shows the distribution of $C$. As expected, the density for developing countries lies to the right of the one for developed countries. In addition, there is a much larger dispersion in $C$ across developing countries. The density for developed countries is more concentrated.

To explore differences in $C$, we report averages for countries by region and by income levels. The lowest labor mobility costs are in North America, 2.21, and in Western Europe, 2.61. In developing countries, the highest average estimated Cs are for Sub-Saharan Africa (4.00), Eastern Europe \& Central Asia (3.95), South Asia (3.88), Middle East \& North Africa (3.59), East Asia \& the Pacific (3.46), and Latin America (3.23). When countries are grouped by income level, the estimated costs are 2.70 in High income OECD countries, and 3.05 in High income, non-OECD countries. The highest average $C$, at 4.70, is in Low income countries. The mobility cost in lower middle income countries is 3.70 and in upper middle income countries, 3.60.

We can also explore some correlates of the labor mobility costs. We do this by plotting simple bivariate non-parametric regressions between various country characteristics and the size of the estimated mobility costs. We present here only a few representative results and provide a full set of correlations in the Online Appendix. No causality is implied by this analysis, only simple correlations. Data on these correlates are from the World Development Indicators, and they represent averages for the period 1995-2007.

Panel A) in Fig. 4 describes the correlation between the mobility costs and country well-being. As expected, richer countries, in terms of per capita GDP, tend to show lower mobility costs. In the Online Appendix, we also show a very strong positive correlation with both the 


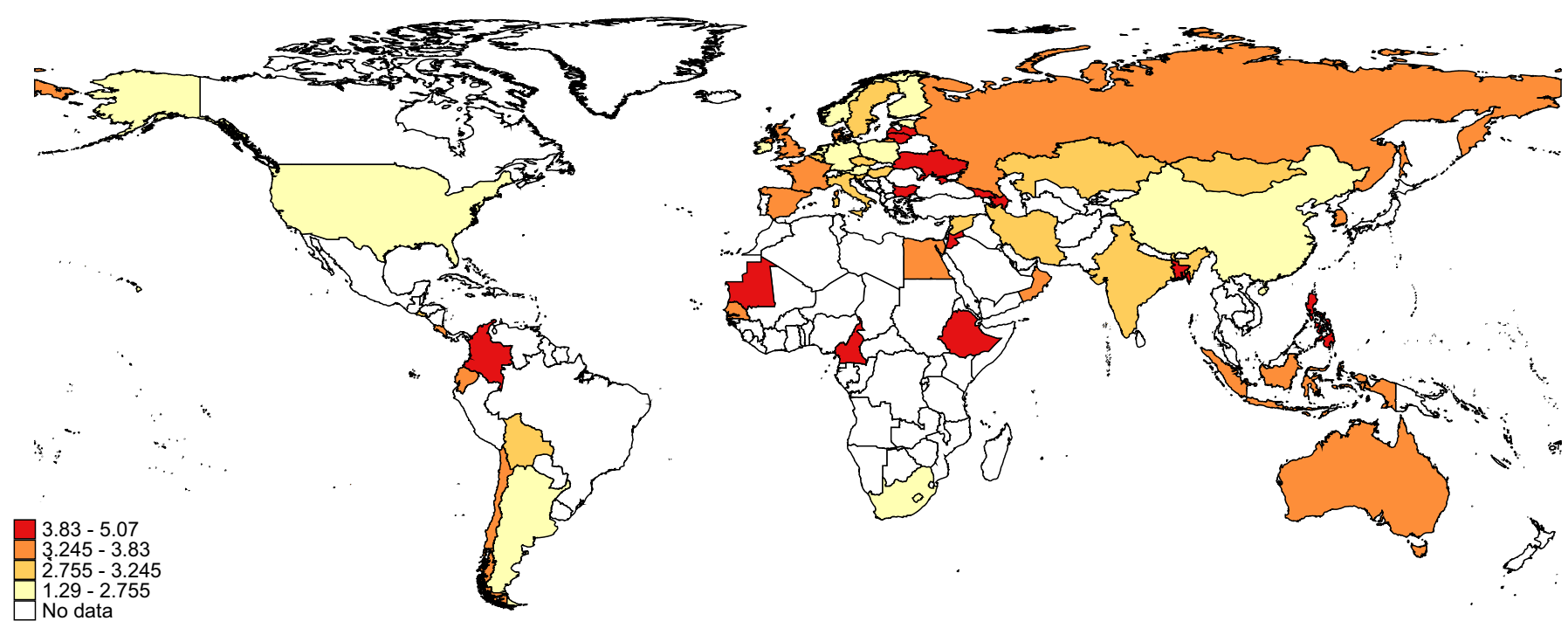

Fig. 2. A mapping of labor mobility costs. Notes: Estimates of labor mobility costs $C$ using UNIDO data.

poverty head-count and the poverty gap. Panel B) documents a positive correlation between the mobility costs and vulnerable employment conditions. More generally, labor mobility costs tend to be higher in countries with less-developed and low-quality labor markets. Finally, we plot in Panel C) of Fig. 4 the correlations with other indicators of constraints and distortions. It is not surprising to find an overall positive correlation between the mobility costs and the number of procedures needed to enforce a contract, or the number of days required to export. This means that labor market rigidities are more prevalent in countries where other types of rigidities and distortions are also present.

\section{Identification assumptions and potential biases}

The estimator has two main sources of bias. First, to solve the model, we need to assume perfect foresight. Unexpected aggregate shocks to the economy, such as labor supply shocks, large domestic macroshocks, or shocks affecting international markets, can thus bias our estimates of the mobility costs. Second, unobserved heterogeneity can also create potential biases (Dix-Carneiro, 2014; Lee and Wolpin, 2006). If workers are different, self-selection based on those differences can make the expected wage in a sector to be a poor predictor of the wage potentially offered to workers employed in other sectors. For example, if the wage in sector $j$ actually offered to a worker in sector $i$ is lower than the average observed wage used by our estimator (because of unobserved attributes such as skills specific to sector $j$ ), then labor reallocation can be small even with large average wage differences. As a result, our estimate of $C$ can be spuriously large. An additional concern is the lack of data on wages in the non-tradable sector in the UNIDO data. This reduces the degrees of freedom in our data and can introduce noise in the estimation. Finally, we need to examine the implications of our normalization of $\nu$ and the fact that we cannot estimate $C$ and $\nu$ separately.

This section presents a comprehensive assessment of the potential biases of the estimates. We do this in steps. We begin with an assessment based on simulations of our model. We then assess the same biases using micro-data for the U.S.

Table 2

Labor mobility costs descriptive statistics.

\begin{tabular}{|c|c|c|c|}
\hline & Observations & Mean & Standard error \\
\hline & (1) & (2) & (3) \\
\hline All countries & 56 & 3.29 & 0.91 \\
\hline Developed & 25 & 2.76 & 0.75 \\
\hline Developing & 31 & 3.71 & 0.81 \\
\hline \multicolumn{4}{|l|}{ By region } \\
\hline Western Europe & 18 & 2.61 & 0.75 \\
\hline North America & 1 & 2.21 & \\
\hline Eastern Europe \& Central Asia & 9 & 3.95 & 0.72 \\
\hline South Asia & 2 & 3.88 & 1.4 \\
\hline Latin America \& Caribbean & 8 & 3.23 & 0.61 \\
\hline East Asia \& Pacific & 7 & 3.46 & 0.86 \\
\hline Middle East \& North Africa & 6 & 3.59 & 0.76 \\
\hline Sub-Saharan Africa & 5 & 4 & 0.82 \\
\hline \multicolumn{4}{|l|}{ By income group } \\
\hline High income OECD & 21 & 2.7 & 0.78 \\
\hline High income non-OECD & 4 & 3.05 & 0.48 \\
\hline Upper middle income & 16 & 3.6 & 0.83 \\
\hline Lower middle income & 13 & 3.7 & 0.78 \\
\hline Low income & 2 & 4.7 & 0.26 \\
\hline
\end{tabular}

Note: Average of labor mobility costs $C$ for different groups of countries.

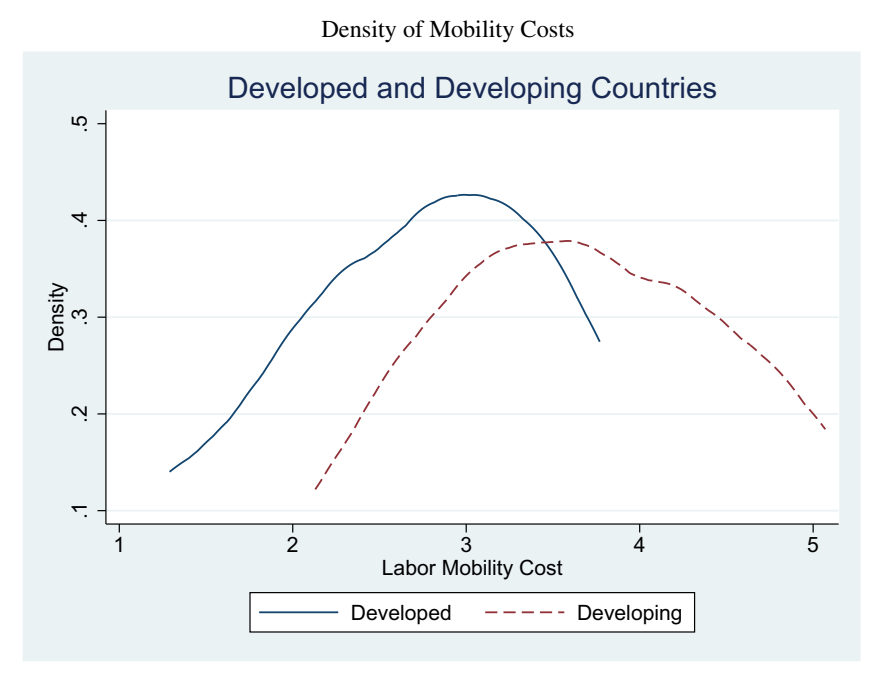

Fig. 3. Density of mobility costs. Notes: Estimates of labor mobility costs $C$ using UNIDO data. Non-parametric density estimators for developed and developing countries. 
A) Country Well-Being

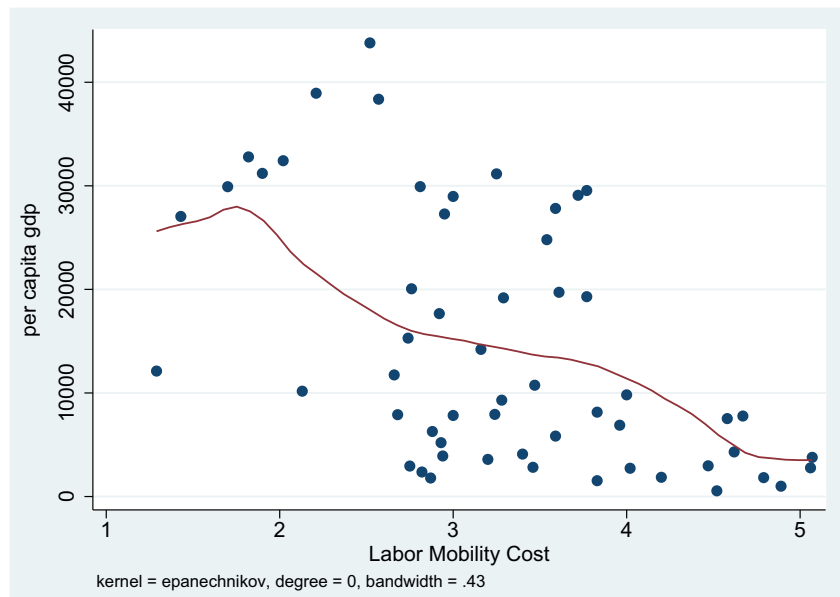

B) Features of Labor Markets

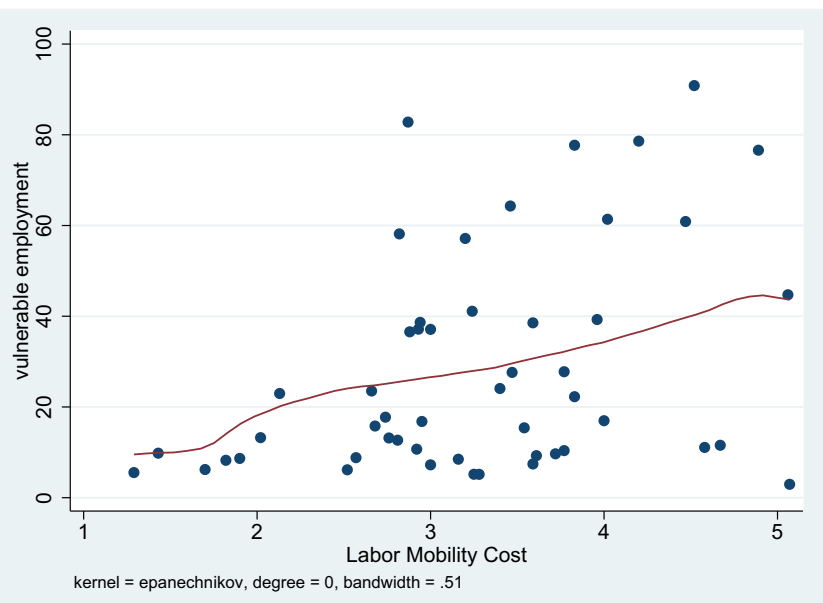

C) Other Distortions: costs of doing business and time to export (in days)
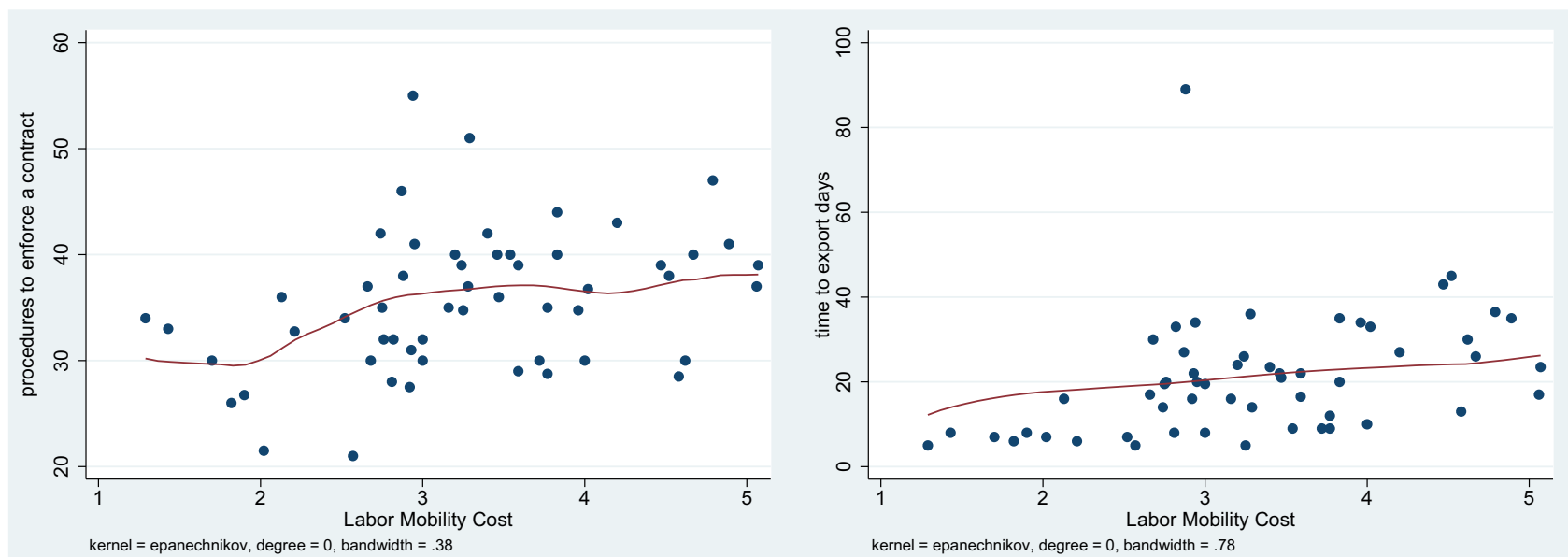

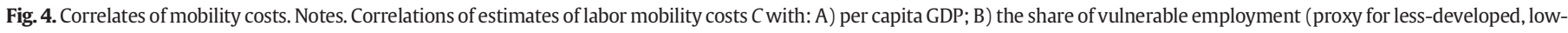
quality labor markets); C) number of procedures needed to enforce a contract and time required to export.

\subsection{Monte Carlo simulation results}

We can learn some of the properties of our estimator with Monte Carlo simulations. The basic structure of our Monte Carlo experiments is simple. We simulate the model $\mathrm{N}=500$ times using $C=2.212$ and $\nu=0.60$. These correspond to the U.S. estimates, which we use here for consistency with the micro-data results below. The total number of workers in the simulations is $L=500,000$, there are 10 time periods

Table 3

Monte Carlo experiments.

\begin{tabular}{llll}
\hline & & Mean & \multicolumn{2}{l}{ Std. error } \\
& True & 2.212 & - \\
\hline Scenario 1 & Basic & 2.174 & 0.064 \\
Scenario 2 & $\nu=0.54$ & 2.024 & 0.053 \\
Scenario 3 & $\nu=0.66$ & 2.318 & 0.064 \\
Scenario 4 & Full wage & 2.184 & 0.049 \\
Scenario 5 & AR(1) Aggregate shocks & 2.258 & 0.119 \\
Scenario 6 & Low unobserved heterogeneity & 2.281 & 0.081 \\
Scenario 7 & High unobserved heterogeneity & 2.529 & 0.138 \\
Scenario 8 & Low unobserved heterogeneity and AR(1) shocks & 2.343 & 0.122 \\
Scenario 9 & High unobserved heterogeneity and AR(1) shocks & 2.551 & 0.175 \\
\hline
\end{tabular}

Note: Results from various Monte Carlo experiments.
$(T=10)$ and 10 sectors. We estimate $C$ from the simulated data using the estimator introduced in the paper.

We repeat the set of simulations under nine different scenarios to assess the identifying assumptions of our estimator. Results are reported in Table 3. Scenario 1 is the basic scenario where we use the model from the paper as is. We assume that the econometrician does not observe the NT sector wages. In row 1 of Table 3 , we estimate $C=2.174$. This estimate is actually quite close to the true parameter $C=2.212$ and they are in fact not statistically different. ${ }^{12}$ This basic scenario thus confirms in simulations that our estimator can recover with a lot of precision the true parameter of the model.

The first set of experiments that we explore with the Monte Carlo simulations are intended to address the role of the normalization of $\nu$. Our estimator compares wage and employment fluctuations. If wage differences are large but workers move little (i.e., the net flows are small), then we estimate a high $C$, given our normalization of $\nu$. However, a large $\nu$ can also account for small employment responses to wage fluctuations. The variance of the utility shock, $\nu$, indicates how much the workers value wage shocks vis-à-vis idiosyncratic utility shocks

\footnotetext{
${ }^{12}$ Note that our Monte Carlo would not match $C$ perfectly because we set $N=500$ due to computational constraints.
} 
(net of the utility compensating differentials). A high $v$ implies a high variance for these shocks and thus a lower weight on wage shocks. In other words, when $v$ is large, the workers care a lot more about the utility shocks than about the wage shocks, so that the relative importance of wage differences decreases. As a result, the employment response to a given wage differential will be small. ${ }^{13}$

There is still the issue of the implications of normalizing $\nu$. Even if $\nu$ is the same across countries, it could be different from the adopted value of 0.6. How different can it be and if so, can this affect the estimates of $C$ ? To answer these questions, we use the Monte Carlo simulations as follows. In Scenario 1, we simulated data with $C=2.212$ and $\nu=0.6$ (and estimated the model using the simulated data and the normalization $v=0.6$ ). In Scenarios 2 and 3, we use the simulated data from Scenario 1 , but sets $\nu=0.54$ and $\nu=0.66$, respectively, in the estimation. The logic of these experiments is to check how robust $C$ is if the normalization of $\nu$ is wrong. In row 2 of Table 3 , we get $C=2.024$, which is very close to the true $C$. In row 3 , we get $C=2.318$, which is also close to the true $C$. These simulations thus show that the estimation of the mobility costs is robust to (small) departures of $\nu$ in a neighborhood of 0.6 , $[0.54,0.66]^{14}$

In Scenarios 4-9, we assess the other major identification assumptions in our estimator. In Scenario 4, we assume that the econometrician observes the NT wages. In row 4 of Table 3, the estimate of $C$ is 2.184 . This is closer to the true parameter $C=2.212$ than the estimate in Scenario 1 (which ignores the wage of the non-traded sector as in the UNIDO data), and has a smaller standard error. Observing wages in the NT sector helps because it adds information to the estimation procedure.

In Scenario 5, we incorporate unobserved AR(1) aggregate shocks to the wages, with variance 0.05 (approximately $5 \%$ of average wages, which is close to the standard error of wage fluctuations in the U.S. data) and persistence parameter 0.8 . The shocks are unobserved by the econometrician for the entire 10 year sample period. In this case, the estimate of $C$ is 2.258 (row 5 ) so that the baseline $C$ is biased down. This bias is not, however, very large.

Scenarios 6 to 9 add unobserved heterogeneity. In Scenario 6, we incorporate a synthetic version of Roy's self selection model. To do this, we assume that some workers have advantages in certain sectors. Concretely, we work with reference worker type and 9 additional types. These additional types have a $25 \%$ productivity advantage in one sector relative to other sectors, (i.e. they are more productive in that particular sector compared to other sectors, and earn $25 \%$ higher wages than others if they choose that sector). We assume that each type of workers is equally represented by $10 \%$ of the total mass $L$. Types are unobserved and persistent. In row 6 of Table 3, the estimate of $C$ increases to 2.281. In Scenario 7, we allow for stronger worker specificity in their comparative advantage sector, namely we assume that workers have a $50 \%$ productivity advantage. It is not surprising that, with more significant worker heterogeneity, the estimate of $C$ goes up to 2.529. We finally combine the two Roy model experiments with AR(1) aggregate shocks. In rows 8 and 9, we find that $C$ increases to 2.343 and 2.551, respectively. All these Monte Carlo experiments uncover some biases. In the worst case scenario (with large aggregate shocks and strong heterogeneity) the bias is roughly about $15 \%$ of the value of the estimate.

\footnotetext{
${ }^{13}$ Since we are normalizing $\nu$ for all countries, we are creating a hierarchy of countries based on the labor mobility costs $C$, which is the average, common, cost of various labor market frictions. Parameter $v$ is instead related to the idiosyncratic cost of those frictions. If $\nu$ were more homogeneous across countries than $C$ is, then the ranking of countries based on our estimates is thus a reasonable ranking of labor market frictions.

${ }^{14}$ In the Online Appendix, we perform additional robustness tests. In particular, we show that the simulation results from our model are also robust to small departures from the normalization of $\nu$
}

\subsection{Assessment using micro-data}

We now assess the potential biases using micro-data from the U.S. Current Population Survey (CPS). Let $C_{\text {。 }}$ be the true value of $C$, and let $C_{W}$ be our estimator. We can write

$C_{W}=C_{\circ}+B_{1}+B_{2}+B_{3}$

where $B_{1}$ is the bias caused by aggregate shocks, $B_{2}$ is the bias caused by unobserved heterogeneity, and $B_{3}$ is the bias (or noise) generated by our treatment of the non-traded sector. The baseline to which we compare our estimates is the MLE estimator of Artuc and McLaren (2014) and Artuc, Bet, Brambilla and Porto (2014) using the U.S. CPS micro-data (as described above). The estimate for the baseline is $C_{\circ}=1.762$ (with a standard error of 0.288 ) and $\nu=0.596 .{ }^{15}$ See Table 4 . As it can be seen, the estimates of $C$ for the U.S. using micro data from the CPS or aggregate data from UNIDO are not that different. In fact, given the estimated standard errors, the estimates are not statistically different.

We can also improve these estimates by purging wages from worker heterogeneity (observed in the CPS data but unobserved in the aggregate data). To do this, we run Mincer regressions of log wages on sector dummies and worker characteristics (gender, marital status, education, age) and use the coefficient on the sector dummies as wages in the Artuc and McLaren (2014) estimator. This delivers $\hat{C}_{M}^{p}=1.636$ and $\nu=0.60$ (row 2 of Table 4). Note that worker heterogeneity creates an estimated bias of 0.126 (around 7\%) in the CPS and MLE method. Given the standard error of 0.174 , this bias is not statistically significant.

Using $\nu=0.60$ and our minimum distance estimator, we estimate $C$ for the U.S. with aggregated CPS data and we get $\hat{C}_{W}=C_{0}+B_{1}+B_{2}+$ $B_{3}=2.081$ (row 3 of Table 4). Comparing $\hat{C}_{W}=2.081$ with $\hat{C}_{M}^{p}=$ 1.636 , we calculate an overall estimated bias of 0.445 , roughly equivalent to $27 \%$ of $C$. The standard error of $\hat{C}_{W}$ is 0.42 , and consequently the difference with $\hat{C}_{M}$ is not statistically significant either.

To tell apart the different biases, we can first estimate $C$ using our method and purged wages from CPS (using a Mincer wage regression as before). We estimate $\hat{C}_{W}^{1}=C_{\circ}+B_{1}+B_{3}=1.643$ so that, with our procedure, the estimated bias created by unobserved heterogeneity is $B_{2}=0.438$. Furthermore, we can estimate a version of our model where we include the non-traded sector wages and employment as additional units of observations. This gives $\hat{C}_{W}^{2}=C_{0}+B_{1}+B_{2}=1.946$ (row 4 of Table 4 ). This pins down estimates for $B_{3}=0.135$. And, given $B_{2}=0.438$, we pin down $B_{1}=-0.128$.

This means that worker heterogeneity that is unaccounted for in our procedure creates a positive estimated bias of $B_{2}=0.438$. Thus, indeed, unobserved heterogeneity can lead to spuriously large $C$ in our model. In addition, our treatment of the non-traded sector in which we calibrate $\mathbf{u}^{1}$ adds $B_{3}=0.135$ to the overall estimated bias. Ignoring labor mobility to the residual sector thus inflates our estimate of $C$. By contrast, aggregate shocks drive our estimates down, with $B_{2}=-0.128$. Large unforeseen aggregate shocks can make people move across sector more, given the wage differentials, thus creating a spuriously lower $C$.

To conclude, these exercises uncover some of the biases that can arise in our estimation procedure. The different estimators are not, however, statistically different from one another. Consequently, the presence of potential biases should not, we believe, prevent us from using our estimates to assess trade policy (as we assess the cost of adjustment to trade in the following section). Rather, these caveats should be acknowledged and some sensitivity analysis may be in order.

\section{The estimates at work: simulating labor market responses}

Our estimates of $C$ have a high descriptive value, especially for developing countries. They can be used to characterize and assess differences in labor market frictions across countries. In this section, we illustrate

\footnotetext{
${ }^{15}$ Recall that this is the baseline we used to derive the normalization of $\nu$.
} 
Table 4

Estimates of potential biases.

\begin{tabular}{|c|c|c|c|c|c|}
\hline & & Aggregate shocks & Unobserved heterogeneity & Treatment NT sector & Overall bias \\
\hline & C & $B_{1}$ & $B_{2}$ & $B_{3}$ & $B_{1}+B_{2}+B_{3}$ \\
\hline \multicolumn{6}{|l|}{ U.S. CPS data } \\
\hline \multicolumn{6}{|l|}{ Artuc \& McLaren } \\
\hline Aggregate wage data $\left(\hat{C}_{M}\right)$ & $\begin{array}{l}1.762 \\
(0.288)\end{array}$ & & & & \\
\hline Purged wage data $\left(\hat{C}_{M}^{p}\right)$ & $\begin{array}{l}1.636 \\
(0.174)\end{array}$ & & 0.126 & & 0.126 \\
\hline \multicolumn{6}{|l|}{ Artuc, Lederman, Porto } \\
\hline Baseline $\left(\hat{C}_{W}=C+B_{1}+B_{2}+B_{3}\right)$ & $\begin{array}{l}2.081 \\
(0.422)\end{array}$ & - & - & - & 0.445 \\
\hline Purged wages $\left(\hat{C}_{W}^{1}=C+B_{1}+B_{3}\right)$ & $\begin{array}{l}1.643 \\
(0.374)\end{array}$ & - & 0.438 & - & 0.445 \\
\hline With NT wages $\left(\hat{C}_{W}^{2}=B_{1}+B_{2}\right)$ & $\begin{array}{l}1.946 \\
(0.423)\end{array}$ & - & - & 0.135 & 0.445 \\
\hline Biases & & -0.128 & 0.438 & 0.135 & \\
\hline \multicolumn{6}{|l|}{ U.S. UNIDO data } \\
\hline Artuc, Lederman, Porto & $\begin{array}{l}2.212 \\
(0.526)\end{array}$ & - & - & - & 0.576 \\
\hline UNIDO data bias & & & & & 0.131 \\
\hline
\end{tabular}

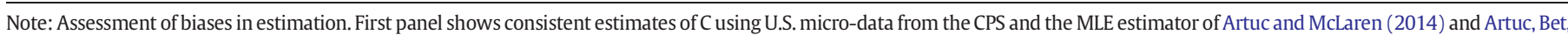

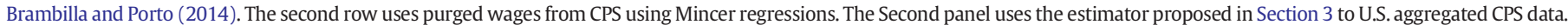
The last panel shows the estimate of $C$ for the U.S. using aggregate UNIDO data.

how to use those same estimates to simulate labor market responses to a trade shock and to derive measures of trade adjustment costs. Given the limitations of our data, we work with simple simulations where we shock the price of a sector. We focus on trade shocks to Food and Beverages, but also show simulations to shocks in Textiles. We assume that the price of these goods exogenously and unexpectedly decline by $30 \%$ and we run independent simulations for all the countries in our sample. ${ }^{16}$ All the results that follow should be taken as indications of potential impacts of trade shocks and as a simple illustration of the uses of our estimates of $C$.

To simulate the economy, we need to add more structure into our model. We specify production and demand functions and we calibrate the initial steady state of the economy. When the economy is hit by the trade shock, we solve for the transition path to the new steady state. Details on the structure of the simulations and the algorithms to find the solutions are in Artuc et al. $(2008,2010)$.

On the demand side, we assume Cobb-Douglas preferences

$u=\prod_{g} x_{g}^{\theta_{g}}$,

where $x_{g}$ is the consumption of good $g$ and $\theta_{g}$ is its share of total expenditure. To be consistent across the paper, we work with nine goods, eight traded goods and the non-traded residual sector. We represent those preferences with data on budget shares compiled by the International Comparison Program. ${ }^{17}$

Production functions are also assumed to be Cobb-Douglas

$Q_{g}=A_{g} L_{g}^{\alpha_{g}} K_{g}^{1-\alpha_{g}}$,

where $Q_{g}$ is the physical output of good $g$, $A_{g}$ is a technology parameter, and $L_{g}$ and $K_{g}$ are labor and capital respectively. Labor is imperfectly mobile because of the moving costs. Instead, capital is assumed to be fixed as in Artuc et al. (2010). ${ }^{18}$ The parameters $\alpha_{g}$ are approximated

\footnotetext{
${ }^{16}$ We do not attempt to develop a global model of trade adjustment. We think about this decline in prices as being generated, for instance, by a decline in the world demand for food and thus in food international equilibrium prices. A global model of trade is, however, doable, if we impose heavy structure to a global model such as Hoekman and Olarreaga (2008).

17 Details can be found at http://siteresources.worldbank.org/ICPEXT/Resources/ICP_ 2011.html.

18 See Artuc et al. (2014a) for simulations with imperfect capital mobility.
}

with the share of the wage bill in value added at a sectoral level. Assuming that each sector pays a wage equal to the marginal product of labor, we then solve for the technology parameters (including differences in capital)

$\widetilde{A}_{g}=\frac{1}{\alpha_{g}} w_{g} L_{g}^{1-\alpha_{g}}$,

where $\widetilde{A}_{g}=A_{g} K_{g}^{1-\alpha_{g}}$. Note that there is an important difference in the treatment of the traded and residual sectors. For the traded sectors, the UNIDO data include wages and employment and thus we can easily recover $\tilde{A}_{g}$. For the residual sector, we only observe $L_{g}$. For the purpose of the initial calibration, we thus set the wage to the average wage of the economy.

We focus first on shocks to Food and Beverages. The transitional dynamics of each country are interesting and revealing in themselves. But rather than attempting to describe all these dynamics, we prepared a typology of responses that are prevalent in our sample. In Fig. 5, we illustrate the responses of employment allocations and wages for two developing countries. Philippines, a country at the very top of the labor mobility cost hierarchy with $C=5.06$, is in the top panel. China, a country with relatively low costs $C=2.75$ for the developing world, is at the bottom. ${ }^{19}$ Each graph shows six responses using solid lines for wages and dashed lines for employment. The responses of the affected sector (Food and Beverages) are plotted with a thick line and the responses of the residual sector, with a medium-thick line. To simplify the presentation of the results, we aggregate all the remaining traded sectors into one. These responses are plotted with a thin line. To streamline the exposition, all our results are presented as proportional changes relative to the initial steady state.

On impact, the real wage in Food and Beverages declines. The decrease in food prices causes a loss of profitability in the sector that translates one to one to nominal wages. There is also a decline in the price index (CPI) that is proportional to the food share, which is less than 1 . Real wages in food thus decline. Real wages increase in the rest of the economy, both in the residual sector and in other manufactures, because of the increase in purchasing power (with constant nominal wages and a lower CPI).

There are sizeable differences in these initial responses because the weight of food in the price index varies across countries. Ceteris paribus,

\footnotetext{
${ }^{19}$ A full set of simulation results for all countries can be found in the Online Appendix.
} 
A) High-C: Philippines

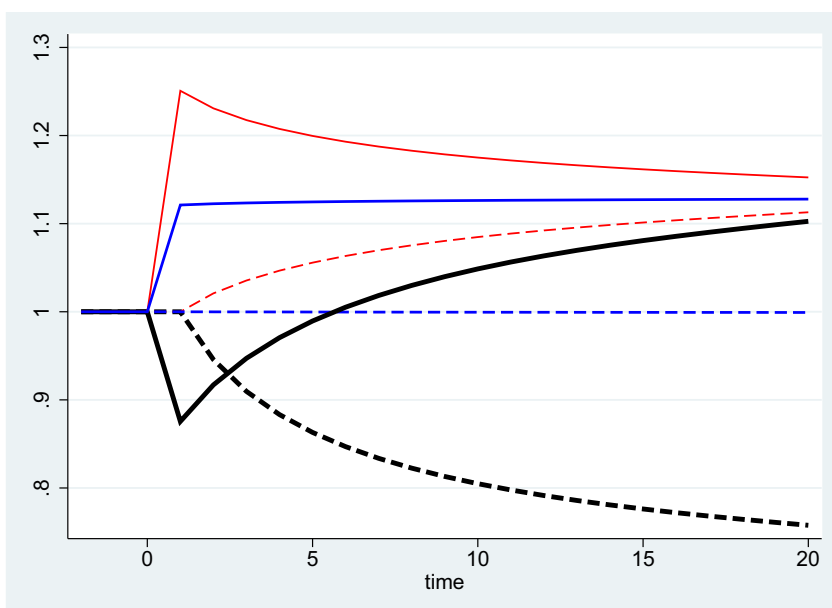

B) Low-C: China

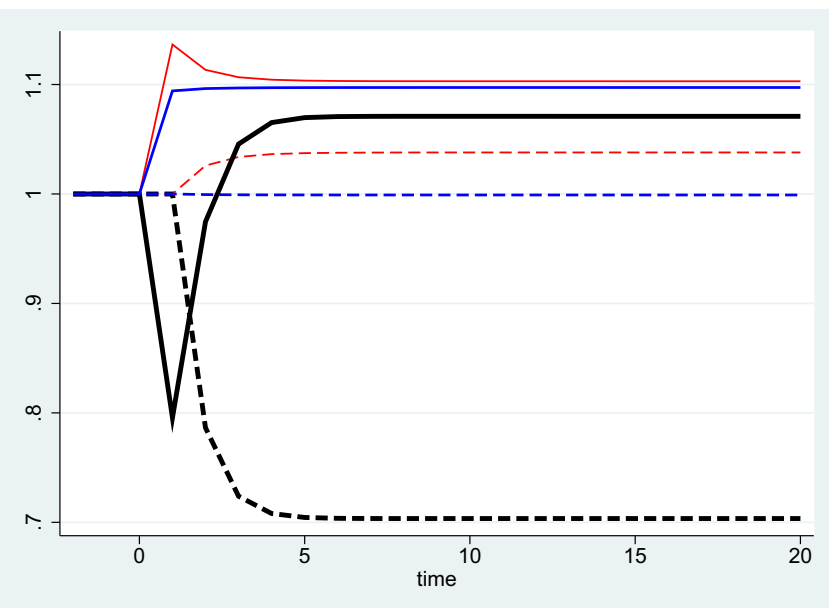

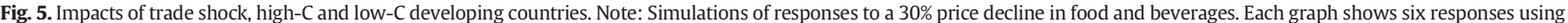

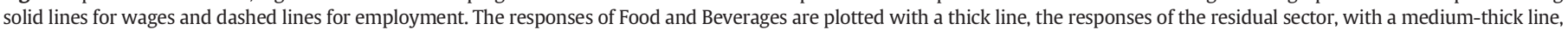
and the responses of the remaining traded sectors, with a thin line. The graphs show proportional changes relative to the initial steady state.

a large food share implies a large reduction in the CPI and, consequently, a smaller initial decline in real wages in the sector (independently of the mobility costs). In Mauritania and Ethiopia, for example, the initial decline in real wages is roughly $10 \%$, and the food shares are 0.67 and 0.58 , respectively. In the United States, where the food share is about 0.10 , the initial drop in real wages is the largest, almost $25 \%$. These results for Mauritania and the United States can be seen in the top panel of Fig. 6.

The resulting changes in intersectoral real wage differentials create incentives for the workers to move away from the food sector. The real wage in the sector thus gradually starts increasing. In many cases, real wages actually recover and are in fact higher in the new steady state than in the initial steady state. This happens when the recovery of the nominal wage during the transition outweighs (in absolute value) the decline in the CPI due to lower prices. The recovery is consequently more likely to be observed in countries with low initial drop in real wages in Food and Beverages. For instance, there is no recovery in many developed countries with low food shares in the CPI (Austria, Germany, Finland, Ireland, Netherlands and the United States).

We can more clearly illustrate how the model works with a diagrammatical representation of a 2-sector economy (Artuc et al., 2014b). Fig. 7 shows the equilibrium. We plot the real marginal product of labor curves in each sector. The initial equilibrium labor allocation (arbitrarily chosen) occurs at point A, i.e. not at the intersection of the curves. Note that this equilibrium is consistent with intersectoral wage differences because of the presence of the mobility costs. ${ }^{20}$ We illustrate the results of the model with a decrease in the price of good 1 . This makes the real marginal product of labor curve shift down while the real marginal product of labor curve in the other sector shifts up (this is because of the decline in the CPI due to lower consumer price). The top panel of Fig. 7 shows a case where the CPI weight of good 1 is relatively small. In consequence, there is a (relatively) large initial decline in the real wage in sector 1 (point B) and no steady state recovery (point C). The bottom panel of Fig. 7 shows the case where the CPI weight of good 1 is larger. In this case, there is a less pronounced initial drop in real wages in sector 1 (point B). In addition, real wages recover fully and are actually higher in the post-shock steady state (point C).

${ }^{20}$ It should be pointed out, however, that the wage differential is not equal to the mobility cost because of the idiosyncratic shocks. See the discussion in Artuc et al. (2014b).
The recovery also depends on the costs of labor mobility and on the slope of the marginal product of labor. A very low labor share in the production of Food can create a very steep marginal labor product curve. This implies that a given labor re-allocation away from the Food sector generates a larger recovery of the equilibrium wage in the sector. ${ }^{21}$ There are, in fact, significant differences in the time it takes to recover. We illustrate in the bottom panel of Fig. 6 the cases of Bangladesh (left panel) and Bulgaria (right panel). Both countries have comparable mobility costs, $C=4.89$ and $C=4.69$, respectively, but Bangladesh' labor share in food is 0.17 and Bulgaria's is 0.35 . As it can be seen, Bangladesh recovers in 4 years while Bulgaria recovers in 11 .

Employment in the shocked sector declines, as expected, because firms shrink. As workers reallocate, employment in the other traded sectors react proportionately much more than employment in the residual sector because the latter is typically very large. This also shows up in the responses of sectoral wages, which, as already pointed out, increase in both cases. The real wage in other traded sectors first increases, but then declines. However, in no country are the responses reverted (so real wages in the new steady state are always higher than in the initial steady state). In the residual, non-traded sector, the initial increase in real wage roughly perpetuates during the whole transition. This is so for most countries and it is the consequence of the size of the sector. Since the residual sector is very large, compared with other traded sectors in these economies, the (often low) inflow of workers does not affect equilibrium wages to a large extent.

Overall, thus, our findings suggest sluggish responses of the labor market, especially in the affected sector, due to labor mobility costs. This can also be seen by computing, for each country, the number of years needed to converge to within $95 \%$ of the new steady state level of real wages in Food and Beverages. ${ }^{22}$ The results are reported in Fig. 8. Worldwide, the average convergence speed is 5.5 years, but it is slower in developing countries (6.4 years) than in developed countries (4.4 years). There is significant variation in speed. In Jordan, for instance, it takes 12 years to reach $95 \%$ of the steady state; in Bangladesh, Bulgaria, Ukraine, Latvia and Azerbaijan, 11 years; in the Philippines, 10. By contrast, it takes only two years in Estonia, Finland, Germany, Netherlands, Ireland, and the United States. As the graph shows, the convergence speed steadily decreases with $C$.

\footnotetext{
21 In the Online Appendix, we include a 2-sector diagrammatic representation, as in Fig. 7, to explain the role of the slope of the marginal curve.

${ }^{22}$ Other variables, such as employment, produce similar results.
} 
Impacts of Trade Shock

A) Mauritania

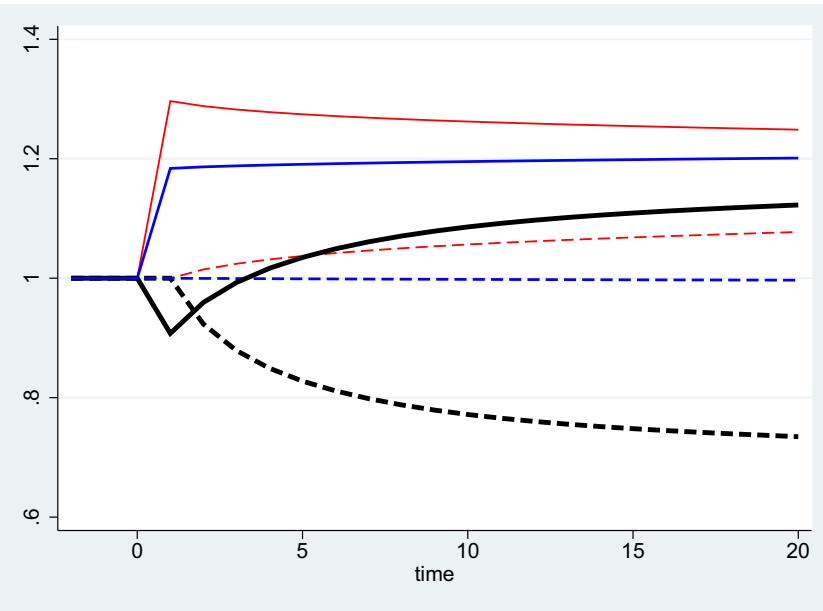

B) United States

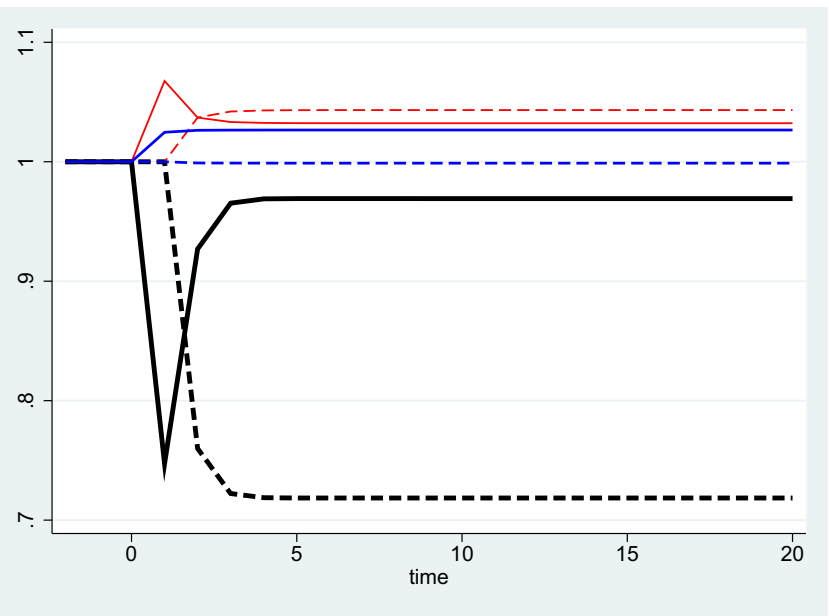

C) Bangladesh

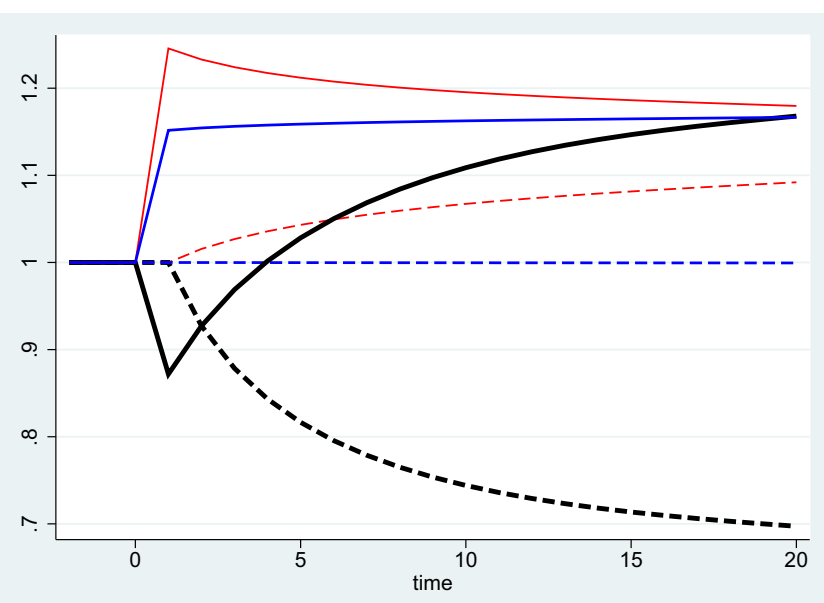

D) Bulgaria

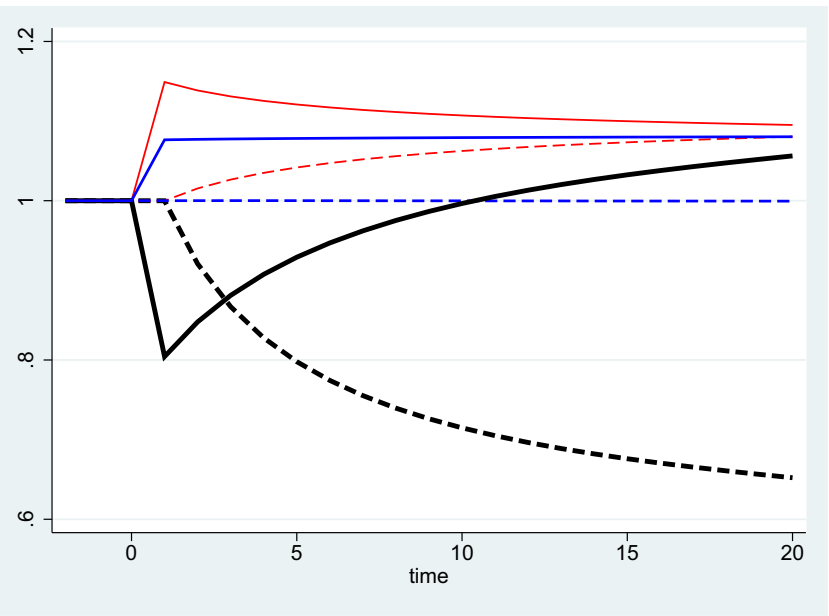

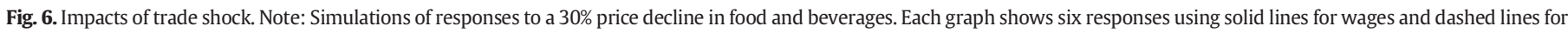

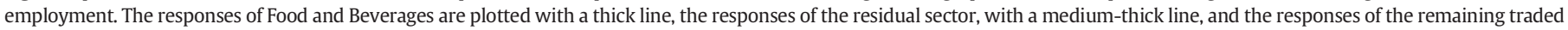
sectors, with a thin line. The graphs show proportional changes relative to the initial steady state.

\subsection{The welfare effects of trade and trade adjustment costs}

We can illustrate how to use our model and our estimates of $C$ to calculate measures of welfare effects from trade and of trade adjustment costs. It is important to note that we are not modeling the trade shocks explicitly, but rather explore the consequences of a decline in the price of a good-Food and Beverages-everywhere in the world caused, for example, by a decline in aggregate demand of Food in developed countries. Alternatively, we could model trade liberalization in each country separately. In this case, the price of Food could increase for net-exporting countries but could decrease for net-importing countries. Performing this exercise requires a typification of countries in netexporters and net-importers. Here, we work with a simple setting of a common shock to all countries in order to be able to show a set of stylized responses to shocks in economies with different labor mobility costs.

The total gains or losses from a trade shock can be calculated from the induced changes in real factor rewards for all factors of production. Since we work with a specific factor model with imperfect labor mobility, the factors of production are the specific factors (in all sectors) and the workers that earn sector-specific wages (due to
C). Since calculating aggregate welfare effects requires additional assumptions on the distribution of those specific factors, we focus in what follows on the workers. Moreover, to more clearly illustrate how $C$ creates welfare effects and costs of trade adjustment, we look at the welfare effects of trade shock for the workers in the affected sector, i.e., Food and Beverages. ${ }^{23}$ As our measure of welfare, we use the workers' values, given by $V_{t}$ in Eq. (6), which is the present discounted utility for a (random) worker in the food sector at

\footnotetext{
${ }^{23}$ We should nevertheless emphasize that a full welfare analysis of the gains from trade is certainly possible in our framework. See our Online Appendix for additional welfare results. In a specific factor model, the specific factor gains if the price of the sector goes up and loses otherwise. Consequently, after the decline in the price of Food and Beverages, the real return to capital (or more generally the specific factor in the sector) will decline and capitalist in the sector will lose. By contrast, capitalists in the rest of the economy will gain. The real rewards to labor can increase or decrease depending on the response of the nominal wage and on the weight of the price change in the consumer price index. Note that, in our model and in contrast to the standard specific factor model, labor is imperfectly mobile. This implies some degree of specificity in labor as well. As a result, the response of the real wage will depend on the sector in which a worker is employed at the time of the shock. Different welfare effects can thus be expected for different workers. In the Online Appendix, we show the results for workers in non-food manufacturers and in the residual sector.
} 
A) Low CPI Weight

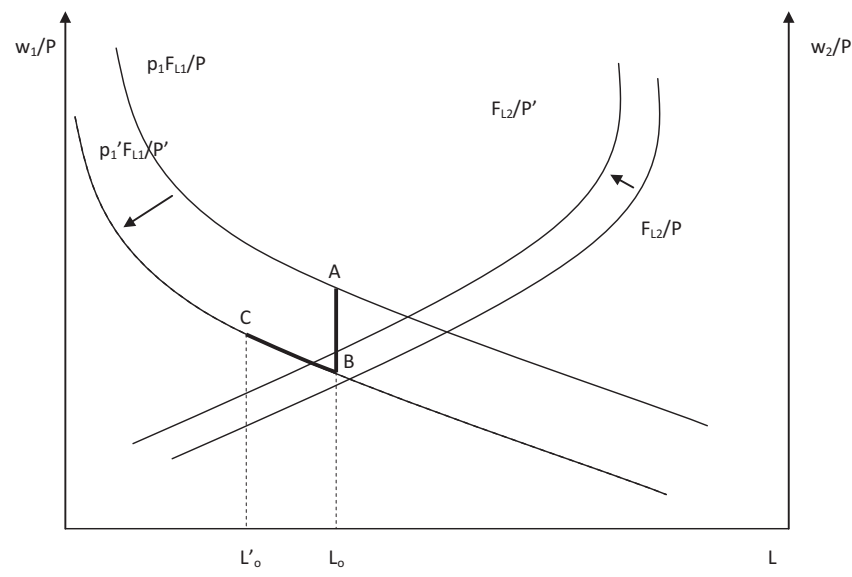

B) High CPI Weight

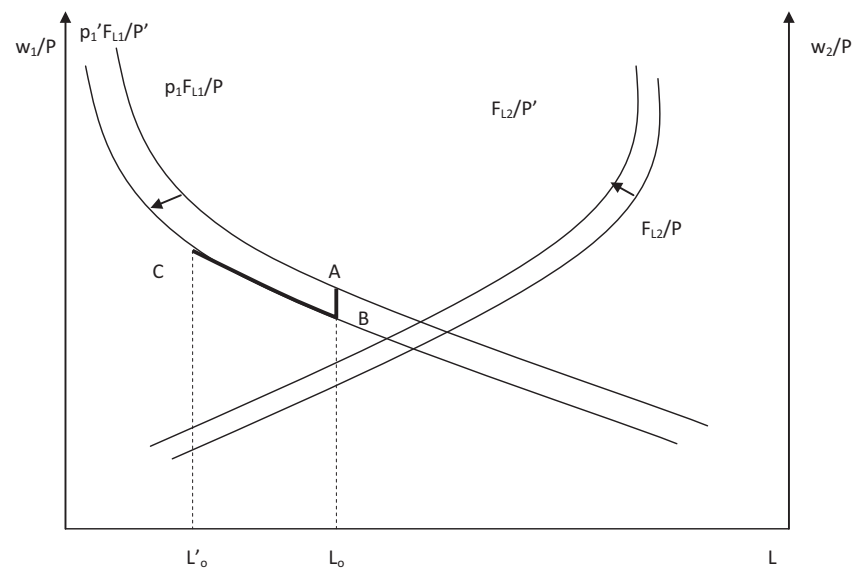

Fig. 7. Diagrammatic representation for a 2-sector economy. Notes. Illustration of the dynamic responses of the model for a 2-sector economy. The top panel depicts a case where the good affected by the trade shock has a low weight in the CPI. Real wages decline a lot in the short run, then increase but never reach the pre-shock steady state. In the bottom panel, the CPI weight of the good in question is higher. The initial drop in real wages is consequently smaller, wages then increase and end up being higher in the post-shock steady state than in the pre-shock steady state.

time $t$. Note that our model generates bilateral flows of workers between sectors during the transition and during the steady statethe difference being that wages change in the transition but the wage differentials are constant in the steady state. In consequence, when we refer to trade adjustment costs for workers in Food and Beverages, we are making a statement about a random worker that may, or may not, switch sectors.

Let $V_{0}^{F}$ and $V_{\infty}^{F}$ be the welfare of a worker in Food and Beverages in the pre-shock and post-shock steady states. Let $V^{F}$ be the present discounted value of the utility of a worker in the food sector along the transition. The actual welfare effect of trade is given by

$G^{F}=V^{F}-V_{0}^{F}$.

The potential welfare effect of trade in the Food sector is instead given by

$P G^{F}=V_{\infty}^{F}-V_{0}^{F}$.

The differences between the potential and the actual welfare effects of trade in the food sector are caused by the costs of labor mobility, which prevent the economy from instantaneously reaching the

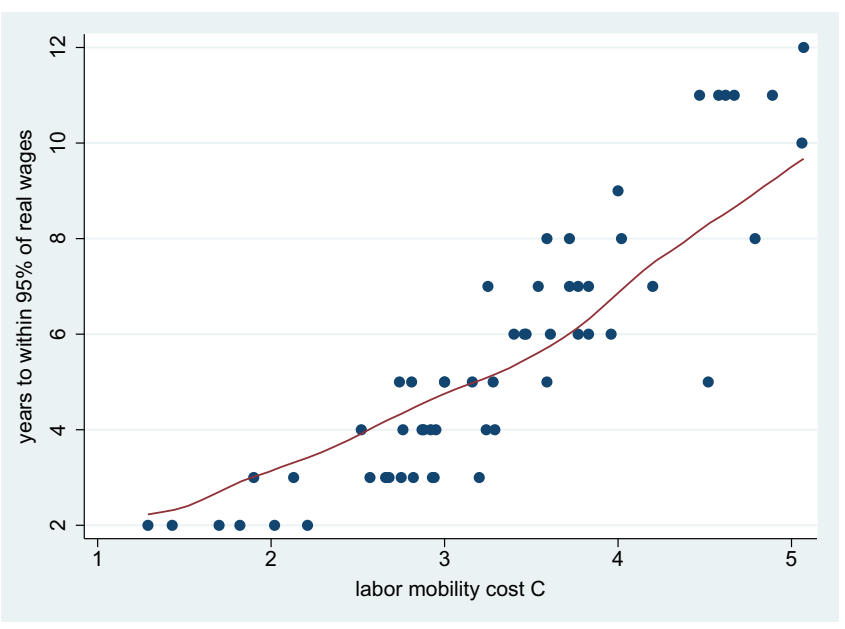

Fig. 8. Convergence to steady state, number of years to within $95 \%$. Notes: Convergence to steady state. Number of years to within $95 \%$ of steady state real wages in food and beverages.

new steady state. As in Davidson and Matusz (2010), this allows us to estimate Trade Adjustment Costs, TAC, as:

$T A C^{F}=V_{\infty}^{F}-V^{F}$.

To help with the interpretation of these measures, we use Fig. 9, which plots a hypothetical transition. Let $b_{t}^{i}$ be the instantaneous utility (including the option value of moving) of a worker in sector $i$ at time $t$, so that $b_{t}^{i}=w_{t}^{i}+\eta^{i}+\Omega_{t}^{i}$ and $V_{t}^{i}=b_{t}^{i}+\beta V_{t+1}^{i}$. In the plot, the pre- and post-shock values $V_{0}^{F}$ and $V_{\infty}^{F}$ are the present discounted value of $b_{0}^{F}$ and $b_{t}^{F}$, respectively. The scenario features positive welfare effects from trade $\left(V_{\infty}^{F}>V_{0}^{F}\right)$ and a transition path that shows an initial decline in welfare and a later recovery. The potential welfare effects of trade are $P G^{F}=$ $A+C$, the actual welfare effects are $G^{F}=C-B$ and $T A C^{F}=A+B$.

The results for developing countries are reported in Table 5. Column 1 reproduces the level of mobility costs $C$. In columns 2 and 3, we show the potential and the actual welfare effects of trade as a share of the value in the initial steady state in the food sector. In our simulations, the potential welfare effects of trade are always positive. Workers in the food sector in all countries stand to gain from lower food prices although the magnitudes vary widely, from a very low 1.49 or $1.71 \%$ in Ireland and the United States, respectively, to almost 25\% in

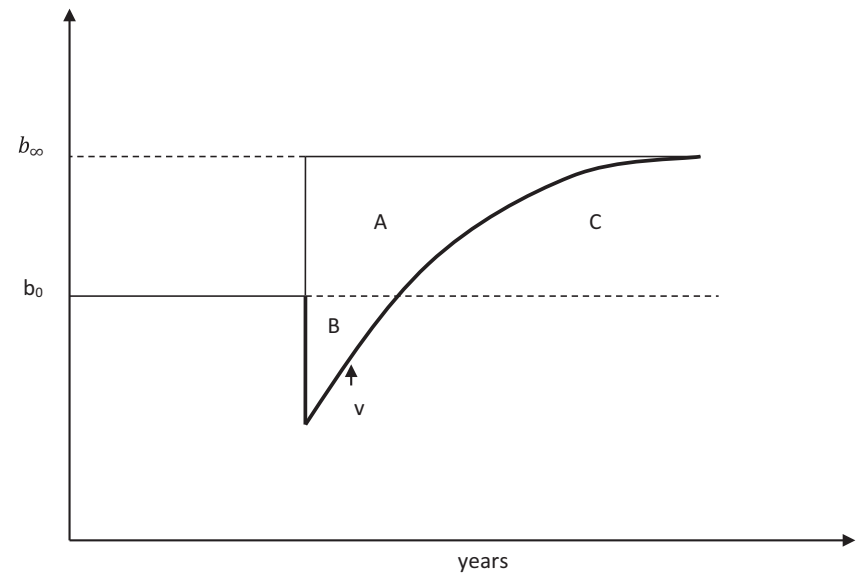

Fig. 9. Trade adjustment costs. Notes: The gains from trade and trade adjustment costs. $b_{t}^{i}$ be the instantaneous utility (including the option value of moving) of a worker in sector $i$ at time $t$, so that $b_{t}^{i}=w_{t}^{i}+\eta^{i}+\Omega_{t}^{i}$ and $V_{t}^{i}=b_{t}^{i}+\beta V_{t+1}^{i}$. The potential gains from trade are $P G=A+C$, the actual gains are $G=C-B$ and the trade adjustment costs are $T A C=$ $A+B$ 
Table 5

Welfare effects from trade and trade adjustment costs workers in Food \& Beverages.

\begin{tabular}{|c|c|c|c|c|c|c|}
\hline & \multirow[t]{2}{*}{ C } & \multicolumn{2}{|c|}{$\begin{array}{l}\text { Welfare effects } \\
\text { from trade }\end{array}$} & \multicolumn{3}{|c|}{ Trade adjustment costs } \\
\hline & & Potential & Actual & $\begin{array}{l}\text { Initial } \\
\text { value }\end{array}$ & $\begin{array}{l}\text { Potential } \\
\text { welfare }\end{array}$ & $\begin{array}{l}\text { Actual } \\
\text { welfare }\end{array}$ \\
\hline Jordan & 5.07 & 6.39 & 1.52 & 4.88 & 76.29 & 321.68 \\
\hline Philippines & 5.06 & 10.38 & 5.23 & 5.15 & 49.59 & 98.36 \\
\hline Bangladesh & 4.89 & 12.87 & 8.16 & 4.70 & 36.57 & 57.65 \\
\hline Mauritania & 4.79 & 14.62 & 9.68 & 4.94 & 33.80 & 51.05 \\
\hline Bulgaria & 4.67 & 5.61 & 0.34 & 5.27 & 94.01 & 1570.40 \\
\hline Ukraine & 4.62 & 12.36 & 6.14 & 6.22 & 50.30 & 101.21 \\
\hline Latvia & 4.58 & 5.92 & 0.37 & 5.54 & 93.69 & 1485.76 \\
\hline Ethiopia & 4.52 & 7.45 & 4.80 & 2.64 & 35.51 & 55.07 \\
\hline Azerbaijan & 4.47 & 24.55 & 18.89 & 5.66 & 23.05 & 29.96 \\
\hline Cameroon & 4.2 & 7.36 & 4.36 & 3.00 & 40.82 & 68.97 \\
\hline Georgia & 4.02 & 7.80 & 4.41 & 3.39 & 43.50 & 76.99 \\
\hline Lithuania & 4 & 7.69 & 3.29 & 4.40 & 57.21 & 133.69 \\
\hline Colombia & 3.96 & 6.76 & 3.53 & 3.23 & 47.74 & 91.35 \\
\hline Costa Rica & 3.83 & 3.26 & -0.27 & 3.53 & 108.29 & -1306.43 \\
\hline Senegal & 3.83 & 8.11 & 5.72 & 2.39 & 29.49 & 41.83 \\
\hline Ecuador & 3.59 & 4.36 & 1.94 & 2.42 & 55.43 & 124.39 \\
\hline Chile & 3.47 & 3.42 & 1.10 & 2.32 & 67.77 & 210.27 \\
\hline Indonesia & 3.46 & 11.28 & 9.02 & 2.27 & 20.09 & 25.14 \\
\hline Egypt & 3.4 & 7.18 & 4.86 & 2.31 & 32.23 & 47.56 \\
\hline Russia & 3.28 & 11.01 & 8.20 & 2.81 & 25.54 & 34.31 \\
\hline Iran & 3.24 & 6.94 & 5.00 & 1.93 & 27.88 & 38.66 \\
\hline Bolivia & 3.2 & 5.29 & 3.71 & 1.58 & 29.87 & 42.59 \\
\hline Romania & 3 & 9.13 & 7.11 & 2.02 & 22.10 & 28.37 \\
\hline Syrian Arab Republic & 2.94 & 9.32 & 7.73 & 1.58 & 17.01 & 20.49 \\
\hline El Salvador & 2.93 & 4.59 & 3.11 & 1.48 & 32.18 & 47.45 \\
\hline Kazakhstan & 2.88 & 6.31 & 4.71 & 1.59 & 25.27 & 33.82 \\
\hline India & 2.87 & 9.55 & 8.53 & 1.02 & 10.69 & 11.97 \\
\hline Mongolia & 2.82 & 7.15 & 5.95 & 1.20 & 16.80 & 20.20 \\
\hline China & 2.75 & 8.25 & 7.05 & 1.20 & 14.53 & 17.01 \\
\hline South Africa & 2.68 & 6.20 & 5.02 & 1.18 & 19.00 & 23.46 \\
\hline Argentina & 2.13 & 4.65 & 4.06 & 0.59 & 12.64 & 14.47 \\
\hline
\end{tabular}

Note: Welfare effects of trade and trade adjustment costs for workers in the food sector following a decrease of $30 \%$ in the price of food and beverages.

Azerbaijan and to almost $13 \%$ in Bangladesh. The reason why a decline in the price of Food and Beverages causes potential welfare gains in the food sector is twofold. As shown above, nominal wages in F\&B decrease and this represents a welfare loss. However, as labor reallocates, the real wage in the food sector recovers and, in many cases, actually overshoots its initial steady state value. In addition, lower food prices raise the real wage, not only in the food sector but also in other sectors of the economy. In the model, the intertemporal welfare of a worker $V$ has two components, the real wage and the option value associated with the probability of future labor choices (possibly implying a switch of sectors). Thus, even though the real wage of a food worker may initially decline following the trade shock, the increase in the real wage in the rest of the economy provides an option value that helps raise overall welfare. Our results suggest that, for all countries, the new steady state level of intertemporal welfare for a food worker is actually higher than the pre-shock welfare. Among developing countries, the potential welfare effects of trade for a food worker are equivalent to $8.12 \%$ of initial welfare.

The actual welfare effects of trade for food workers also tend to be positive. They are also quite large: for developing countries, the welfare impact of trade (as a share of initial welfare) is 5.15\%. This is surprising because of the initial drop in the real wage that we documented in Fig. 5-which means that, along the transition, welfare first declines but then recovers. The results from our simulations suggest that, in 54 out of 57 countries, the future gains from lower food prices more than compensate the short-run losses (in terms of Fig. 9, area $C$ is larger than area $A$ ). Among developing countries, only Costa Rica would actually lose from lower prices. This is because the initial drop in welfare is very pronounced (almost 20\%) and the recovery takes a long time ( 8 years). The actual welfare effects of trade in the food sector are smaller than the potential welfare effects of trade because of the costs of labor mobility. In countries with low $C$ (e.g., Finland or Germany) the differences are negligible, but in countries with high $C$, such as Jordan, Philippines, Ukraine, and Azerbaijan, the differences can be sizeable.

In all countries, the trade adjustment costs $T A C^{F}$ in the food sector are positive. This can be seen in column 4 of Table 5 , which shows TAC ${ }^{F}$ as a share of initial values (always in Food \& Beverages). In low-C countries, and in fact in most developed countries, these costs are very low. As expected, developing countries with higher $C$ face much larger $T A C^{F}$. In Ukraine, for instance, $T A C^{F}$ are equivalent to $6.22 \%$ of the initial welfare of a food worker. In Azerbaijan, Latvia, Bulgaria and Philippines, $T A C^{F}$ s are equivalent to $5.66,5.54,5.27$ and $5.15 \%$ of initial welfare, respectively. In fact, Fig. 10 shows that the level of $T A C^{F}$ increases with $C$. The average $\operatorname{TAC}^{F}$ for developing countries is $2.98 \%$.

In the literature, TAC is typically reported as a share of the total welfare effect of trade (Davidson and Matusz, 2010). This measure gives a sense of the gains from trade that are forgone due to the costs of labor mobility. We report $T A C^{F}$ as a share of the potential and actual welfare impacts from trade in columns 5 and 6 . It is noteworthy that the costs of trade adjustment can represent a very large fraction of the gains from trade. In countries where food workers actually lose from trade (Costa Rica, Great Britain, and Australia), the ratio of $T A C^{F}$ to potential gains is actually greater than 1 (because area $B$ is greater than area $C$ ). In all the remaining countries, $T A C^{F}$ are bounded by $P G^{F}$. The share of $T A C^{F}$ in $P G^{F}$ varies a lot, and the average for developing countries is $41.06 \%$.

The ratio of $T A C^{F}$ to the actual welfare effects for food workers $G^{F}$ can vary widely as well. In Estonia or Finland, the ratios are lower than 10 because these economies can quickly enjoy the gains from trade as the cost of adjusting labor, $C$, is relatively low. In other cases, $T A C^{F}$ is huge. In Bulgaria, $T A C^{F}$ can be more than 15 times higher than the actual welfare effects of trade, and in Chile more than twice as high. The average for developing countries is 118.9 , so $T A C^{F}$ and $G^{F}$ are similar, but the median is 47.5. The size of $T A C^{F}$, in these cases, is dictated by the various parameters of the model, not only by $C$. For instance, the ratios are roughly the same in Mauritania, a country with one of the highest $C$, as in Norway, a country with a low $C$. A large mobility cost makes $T A C^{F}$ large and $G^{F}$ small, so the ratio tends to be high in these cases. But a large share of food prices in the CPI will create a large $G^{F}$, for a given $T A C^{F}$, and thus a lower relative importance of trade adjustment costs.

The model allows us to shock prices in other sectors (as well as other parameters) and thus enrich the analysis. For example, an interesting observation follows from shocking the textile sector. In the UNIDO data, the textile sector tends to be larger than the food sector (in terms of employment). In turn, the weight of Textiles and Clothing in the consumer price index is much smaller than the weight of food. As

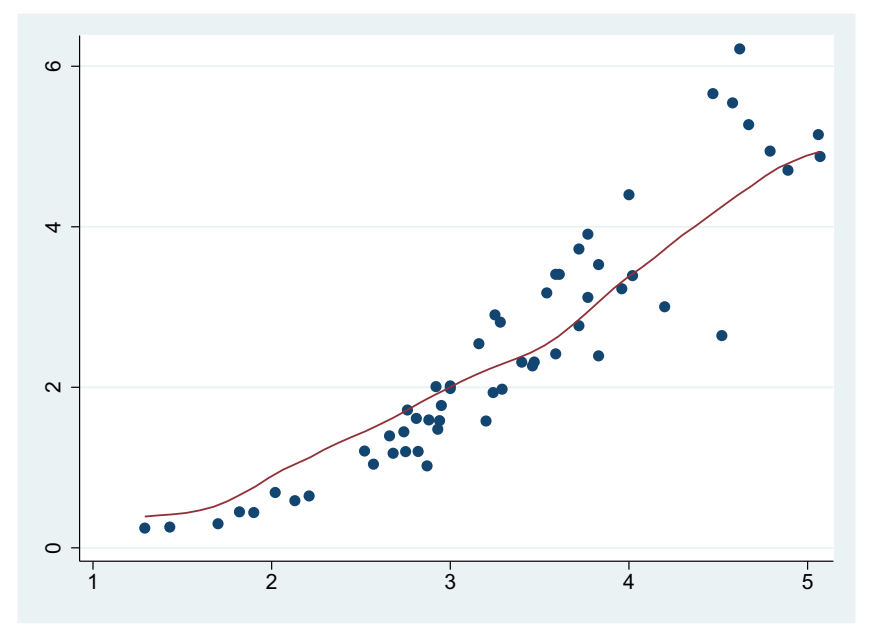

Fig. 10. Trade adjustment costs and labor mobility costs. Notes: Correlations of estimates of labor mobility costs $C$ with estimates of trade adjustment costs. 
Overshooting in Welfare Losses

Textiles in Bangladesh

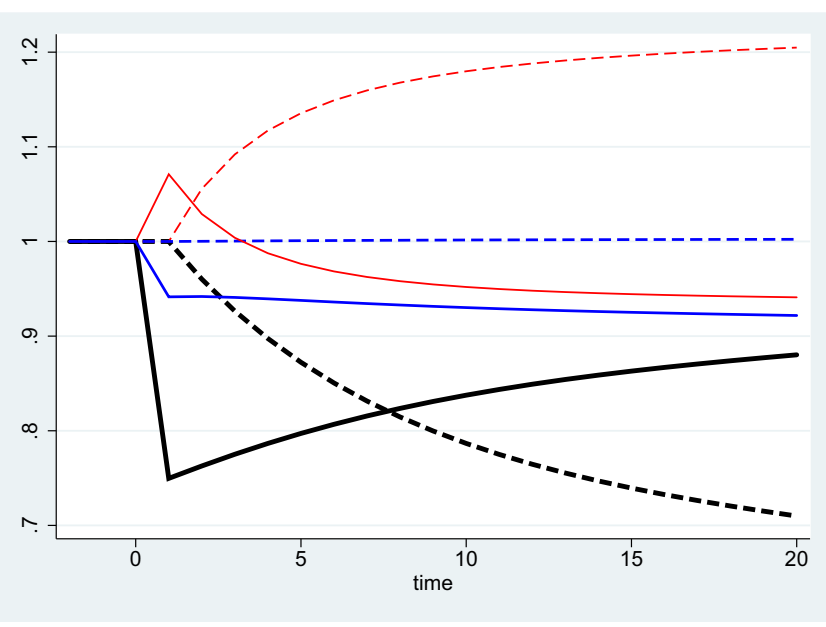

Fig. 11. Overshooting in welfare losses. Textiles in Bangladesh. Notes: Simulation results following a $30 \%$ price decline in Textiles in Bangladesh. The short run welfare loss overshoots the post-shock steady state level of welfare, thus creating positive trade adjustment costs even in the presence of losses from trade.

a result, there will be larger losses from wage responses in the textile sector, and lower gains from CPI changes, thus conducing to welfare losses, both actual and potential, across most countries. However, for those countries, the trade adjustment costs in Textiles, $T A C^{T}$ is positive. This is interesting because it is often argued that, when there are (potential) welfare losses from trade, factor adjustment costs can actually protect workers in the short-run. In other words, when labor is imperfectly mobile, the gradual adjustment to the steady state may ameliorate the short-run losses associated with the loss of protection. In our model, the short-run welfare loss of a textile worker overshoots the post-shock steady state welfare level so that the short-run losses are actually larger than the long-run losses. Fig. 11 presents the case of Bangladesh. This implies positive $T A C^{T}$. In other words, textile workers in Bangladesh are worse off under mobility costs, even if they would lose in the frictionless model.

\section{Conclusions}

The premise of our paper is that, in the presence of labor market frictions, trade shocks can have distinct dynamic effects on wages and employment. To explore this idea, we proposed an estimator of labor mobility costs and we built a map of those costs across the developing world. In line with the literature, we estimate large costs of labor mobility, especially for developing countries. These costs, however, vary a lot across countries. They are negatively correlated with various measures of development (per capita GDP, educational attainments) and positively correlated with other frictions, distortions and constraints in the economy.

Our estimates can be used to assess policies. We combined the structural model with the estimated labor mobility costs to simulate the responses of labor markets to trade shocks in developing countries. These simulations allowed us to illustrate the interplay between labor market frictions and trade shocks and to quantify the gains from trade and the trade adjustment costs. We find that transitions are long,
6 years on average, and longer in countries with higher mobility costs. This creates trade adjustment costs that are typically large, and larger for countries with higher costs.

We think about our estimates of labor mobility costs as a useful tool for policy analysis. We show here that our model and estimator work well with readily available aggregate data. Importantly, if more detailed data could be compiled, the estimation and the simulation results can be improved to account for workers heterogeneity (by for example estimating different costs for skilled and unskilled workers), to incorporate informality, or to better deal with the non-manufacturing sector.

\section{Appendix A. Supplementary data}

Supplementary data to this article can be found online at http://dx. doi.org/10.1016/j.jinteco.2014.10.007.

\section{References}

Artuc, E. and J. McLaren (2014). "Trade Policy and Wage Inequality: A Structural Analysis with Occupational and Sectoral Mobility", mimeo World Bank and University of Virginia.

Artuc, E., Chaudhuri, S., McLaren, J., 2008. Delay and dynamics in labor market adjustment: simulation results. J. Int. Econ. 75 (1), 1-13.

Artuc, E., Chaudhuri, S., McLaren, J., 2010. Trade shocks and labor adjustment: a structural empirical approach. Am. Econ. Rev. 100 (3), 1008-1045.

Artuc, E., G. Bet, I. Brambilla, and G. Porto (2014). "Trade Shocks and Factor Adjustment Frictions: Implications for Investment and Labor", mimeo Universidad de La Plata.

Artuc, E., Chaudhuri, S. and J. McLaren (2014). "Some Simple Analytics of Trade and Labor Mobility", mimeo World Bank.

Attanasio, O., Golberg, P., Pavcnik, N., 2004. Trade reforms and income inequality in Colombia. J. Dev. Econ. 74, 331-366.

Coşar, A. K. (2013). “Adjusting to Trade Liberalization: Reallocation and Labor Market Policies," mimeo University of Chicago.

Coşar, A.K., Guner, N., Tybout, J., 2013. Firm dynamics, job turnover, and wage distributions in an open economy. NBER Working Papers 16326.

Davidson, C., Matusz, S.J., 2000. Globalization and labour-market adjustment: how fast and at what cost? Oxf. Rev. Econ. Policy 16, 42-56.

Davidson, C., Matusz, S.J., 2004a. An overlapping-generations model of escape clause protection. Rev. Int. Econ. 12, 749-768.

Davidson, C., Matusz, S.J., 2004b. International Trade and Labor Markets: Theory, Evidence, and Policy Implications. W.E. Upjohn Institute for Employment Research.

Davidson, C., Matusz, S.J., 2006a. Long-run lunacy, short-run sanity: a simple model of trade with labor market turnover. Rev. Int. Econ. 14, 261-276.

Davidson, C., Matusz, S.J., 2006b. Trade liberalization and compensation. Int. Econ. Rev. 47, 723-747.

Davidson, C., Matusz, S.J., 2010. In: Porto, G., Hoekman, B. (Eds.), Modeling, Measuring, and Compensating the Adjustment Costs Associated with Trade Reforms.

Dix-Carneiro, R., 2014. Trade liberalization and labor market dynamics. Econometrica 82 (3), 825-885

Galiani, S., Porto, G., 2010. Trends in tariff reforms and in the structure of wages. Rev. Econ. Stat. 92 (3), 482-494.

Goldberg, P., Pavcnik, N., 2005. Trade, wages, and the political economy of trade protection: evidence from the Colombian trade reforms. J. Int. Econ. 66, 75-105.

Goolsbee, A., Petrin, A., 2004. The consumer gains from direct broadcast satellites and the competition with cable TV. Econometrica 72 (2), 351-381.

Hoekman, B., Olarreaga, M., 2008. Global Trade and Poor Nations. Brookings Institution Press, Washington, DC.

Kambourov, G., 2009. Labour market regulations and the sectoral reallocation of workers: the case of trade reforms. Rev. Econ. Stud. 76 (4), 1321-1358.

Lee, D., Wolpin, K., 2006. Inter-sectoral labor mobility and the growth of the service sector. Econometrica 74 (1), 1-46.

McFadden, Daniel, 1973. Conditional logit analysis of qualitative choice behavior. In: Zarembka, P. (Ed.), Frontiers in Econometrics. Academic Press, New York.

Menezes-Filho, N., Muendler, M., 2011. Labor reallocation in response to trade reform. CESifo Working Paper (March).

Muendler, M., 2010. In: Porto, G., Hoekman, B. (Eds.), Trade Reform, Employment Allocation and Worker Flows.

Wacziarg, R., Wallack, J.S., 2004. Trade liberalization and intersectoral labour movements. J. Int. Econ. 64, 411-439. 